\title{
O PROGRAMA DE VHC DA DNDI E O SISTEMA DE PROPRIEDADE INTELECTUAL: UMA ABORDAGEM DE SAÚDE PÚBLICA PARA A EPIDEMIA DE HEPATITE C $^{1}$
}

\section{THE DNDI'S HCV PROGRAMME AND THE INTELLECTUAL PROPERTY SYSTEM: A PUBLIC HEALTH APPROACH TO THE HEPATITIS C EPIDEMIC}

Marcos Vinício Chein Feres ${ }^{2}$ Leonardo da Silva Sant'Anna ${ }^{3}$ Alan Rossi Silva ${ }^{4}$

\begin{abstract}
Resumo: A exclusividade garantida pelos direitos de propriedade intelectual aparenta ser, paradoxalmente, ao mesmo tempo, uma das justificativas mais importantes da inovação para a indústria farmacêutica e um dos principais mecanismos de obstrução ao acesso às inovações desse setor. Consequentemente, o presente artigo visa a compreender empiricamente como o programa de pesquisa e desenvolvimento de novos tratamentos para Hepatite C, conduzido pela iniciativa Medicamentos para Doenças Negligenciadas (DNDi, sigla em inglês), se relaciona com o sistema de propriedade intelectual vigente. Para tanto, a pesquisa foi construída a partir de um estudo de caso único, holístico e descritivo sobre o tema, de acordo com as definições elaboradas por Robert Yin e com as proposições teóricas formuladas por Susan Sell. Como resultado principal dessa investigação, foi possível teorizar que, por meio da política de propriedade intelectual adotada e da priorização das necessidades de saúde pública, ambos o programa liderado pela DNDi e o próprio modelo institucional da entidade parecem funcionar como um mecanismo de contorno das estruturas e das instituições atualmente erigidas pelo sistema de propriedade intelectual.
\end{abstract}

Palavras-chave: DNDi. Hepatite C. Sistema de propriedade intelectual. Patentes farmacêuticas. Pesquisa empírica em direito.

\begin{abstract}
The exclusivity guaranteed by intellectual property rights seems to be, paradoxically, at the same time, one of the most important justifications for innovation for the pharmaceutical industry and one of the main mechanisms for blocking access to innovation in this sector. Consequently, this paper aims to understand empirically how the research and development program for new treatments for hepatitis C, led by the Drugs for Neglected Diseases initiative (DNDi), relates to the current intellectual property rights system. Therefore, the research was carried out stemming from a holistic, descriptive, single case study on the subject, according to the definitions elaborated by Robert Yin and the theoretical propositions formulated by Susan Sell. As the main result of this investigation, it is possible to theorize that, through the intellectual property rights policy adopted and the prioritization of public health needs, both the program conducted by DNDi and the institution's own institutional model seem to function as a means of bypassing the structures and the institutions currently supported by the intellectual property rights system.
\end{abstract}

Keywords: DNDi. Hepatitis C. Intellectual property system. Pharmaceutical patents. Empirical legal research.

Recebido em 23 de agosto de 2019

Avaliado em 30 de abril de 2020 (AVALIADOR A) Avaliado em 2 de setembro de 2020 (AVALIADOR B)

Aceito em 5 de setembro de 2020

\footnotetext{
1 Este trabalho possui apoio do Conselho Nacional de Desenvolvimento Científico e Tecnológico (CNPq), da Fundação de Amparo à Pesquisa do Estado de Minas Gerais (FAPEMIG), da Fundação de Amparo à Pesquisa do Estado do Rio de Janeiro (FAPERJ), da Universidade Federal de Juiz de Fora (UFJF) e da Universidade do Estado do Rio de Janeiro (UERJ).

2 Doutor em Direito pela Universidade Federal de Minas Gerais; Professor na Universidade Federal de Juiz de Fora; https:// orcid.org/0000-0001-5045-3436; mvchein@gmail.com

3 Doutor em Saúde Pública pela Escola Nacional de Saúde Pública Sérgio Arouca da Fundação Oswaldo Cruz; Professor no Programa de Pós-graduação em Direito e na Graduação da Faculdade de Direito da Universidade do Estado do Rio de Janeiro; https://orcid.org/0000-0002-5192-2844; 1santanna44@gmail.com

4 Mestre em Direito e Inovação pela Universidade Federal de Juiz de Fora; Doutorando em Direito pela Universidade do Estado do Rio de Janeiro; Rua São Francisco Xavier, 524, Maracanã, 20550-900, Rio de Janeiro, Rio de Janeiro, Brasil; https://orcid.org/0000-0001-8242-4189; alanrossi100@gmail.com
} 


\section{Introdução}

O Vírus da Hepatite C (VHC) é um vírus transmitido pelo sangue, que, ao não ser tratado, pode provocar doenças hepáticas crônicas e debilitantes, como a cirrose, a fibrose e o câncer, bem como outros problemas de saúde. Tendo em vista que a maioria das pessoas infectadas por esse vírus é assintomática, ignorando sua própria enfermidade, pode-se dizer que há uma verdadeira epidemia silenciosa dessa doença. Além disso, esse quadro é agravado ainda mais com a possibilidade de coinfecção com o Vírus da Imunodeficiência Humana (VIH), que coloca em risco todo o avanço já alcançado, no âmbito da saúde pública, também em relação a esta outra enfermidade. Os usuários de drogas injetáveis, por exemplo, por serem uma população difícil de encontrar e diagnosticar, são particularmente sujeitos a essa coinfecção e podem também apresentar uma dificuldade especial para continuar o tratamento (DRUGS FOR NEGLECTED DISEASES INITIATIVE, 2018b).

É relevante destacar, ainda, que existem 6 genótipos (GT) ou variedades do VHC, que são distribuídos distintamente em cada região do mundo. O GT 1, por exemplo, é mais comum nos Estados Unidos da América (EUA), o GT 4, no Egito e o GT 6, no Sudeste Asiático. Essa informação se torna especialmente importante, uma vez que os medicamentos adequados para o tratamento do VHC podem variar de acordo com o genótipo a ser tratado (DRUGS FOR NEGLECTED DISEASES INITIATIVE, 2018b).

Atualmente, estima-se que cerca de 71 milhões de pessoas vivam com hepatite $C$ no mundo, resultando na morte de aproximadamente 400 mil pessoas por ano. Além disso, estima-se que $75 \%$ das pessoas infectadas pelo VHC habitam países de média e baixa renda, enquanto $25 \%$ estão em países de renda alta (WORLD HEALTH ORGANIZATION, 2018b). A maior epidemia de hepatite $\mathrm{C}$ do mundo pode ser encontrada na China, onde habitam quase 10 milhões de pessoas infectadas, sendo seguida pelo Paquistão, com 7,2 milhões, pela Índia, com 6,2 milhões, e pelo Egito, com 5,6 milhões de pessoas infectadas pelo VHC. Quase 40\% da população que vive com hepatite C no mundo habita nesses quatro países (POLARIS OBSERVATORY HCV COLLABORATORS, 2017).

Não obstante a gravidade dessa epidemia, o acesso ao diagnóstico e ao tratamento adequado da hepatite C é ainda muito limitado. Estima-se que apenas $20 \%$ das pessoas infectadas pelo VHC foram diagnosticadas e, entre essas pessoas, apenas uma pequena fração teve acesso ao tratamento de fato. Em 2015, por exemplo, somente 7,4\% das pessoas diagnosticadas com VHC haviam iniciado o tratamento para a doença. Ademais, embora o número cumulativo de pessoas em tratamento para essa enfermidade tenha sido de 5,5 milhões, em 2015, apenas cerca de 500 mil puderam receber a mais inovadora classe de medicamentos, mais seguros e de curta duração, conhecidos como Antivirais de Ação Direta (AAD). Em suma, nesse mesmo período, pode-se afirmar que houve mais infecções novas de VHC que pacientes que iniciaram o tratamento para a doença (WORLD HEALTH ORGANIZATION, 2017). 
A partir dessa realidade, a Estratégia Global para as Hepatites Virais da Organização Mundial da Saúde (OMS) estabeleceu como metas que 90\% das pessoas com o vírus da hepatite C sejam diagnosticadas e que 80\% delas sejam tratadas até 2030 (WORLD HEALTH ORGANIZATION, 2018b). Trata-se de um objetivo bastante ambicioso e que pode enfrentar grandes desafios pelo caminho, como a dificuldade de acesso aos tratamentos existentes atualmente, sobretudo, no que se refere aos preços exorbitantes dos $\mathrm{AAD}$ e seus respectivos monopólios patentários. Sem um amplo acesso a essa nova classe de medicamentos será difícil explorar o seu máximo potencial de reverter essa epidemia e a população mais vulnerável estará ainda mais sujeita a enfermidades que poderiam ser perfeitamente curadas e evitadas pelas inovações farmacêuticas da atualidade (DRUGS FOR NEGLECTED DISEASES INITIATIVE, 2018b).

Em consonância com esse objetivo, a iniciativa Medicamentos para Doenças Negligenciadas (DNDi, sigla em inglês), que é uma organização de pesquisa e desenvolvimento (P\&D), sem fins lucrativos, estabeleceu uma estratégia orientada pelas necessidades dos pacientes e criou um programa próprio, com o intuito de buscar um tratamento pangenotípico, simples e acessível para a hepatite C. Isso significa dizer que, para a entidade, o tratamento a ser desenvolvido em seu programa deve ser eficaz contra as seis variedades do VHC (pangenotípico), deve poder ser feito em larga escala (simples) e deve ser facilmente absorvido pelos sistemas de saúde de todos os países (acessível) - configurando-se como uma verdadeira abordagem de saúde pública para essa epidemia (DRUGS FOR NEGLECTED DISEASES INITIATIVE, 2018b).

Nesse contexto, todavia, como a exclusividade garantida pelos direitos de patente aparenta ser uma das justificativas mais prementes da inovação para a indústria farmacêutica e, ao mesmo tempo, um dos principais mecanismos de obstrução ao acesso a essas inovações (MÉDECINS SANS FRONTIÈRES, 2016; PHARMACEUTICAL RESEARCH AND MANUFACTURERS OF AMERICA, 2019; ZAMPIERI, 2015), faz-se necessário investigar empiricamente como o programa de VHC da DNDi se relaciona com o sistema de propriedade intelectual vigente.

A partir das diretrizes metodológicas de Yin (2015) e das proposições teóricas formuladas por Sell (2003), com o intuito de se compreender a abordagem de saúde pública da entidade e a implementação de suas estratégias para garantir a acessibilidade a seu tratamento, a presente pesquisa empírica se configurará como um estudo de caso das interseções entre as atividades do programa estabelecido pela DNDi e as estruturas, instituições e agentes do sistema de propriedade intelectual globalmente estabelecido.

Sendo assim, na primeira seção, realiza-se uma breve explicação das estratégias teóricometodológicas adotadas. Em seguida, na segunda seção, faz-se uma descrição detalhada do caso estudado. Na terceira seção, faz-se uma análise do caso apresentado na seção anterior. E, por fim, conclui-se o presente trabalho com um resumo do caminho percorrido e com os possíveis desdobramentos futuros dessa investigação. 


\section{Estratégias teórico-metodológicas}

De acordo com as definições trazidas por Yin (2015), a presente pesquisa se constitui como um estudo de caso único, holístico ${ }^{5}$ e descritivo sobre a relação entre o programa de VHC da DNDi e o sistema de propriedade intelectual. Nesse cenário, o estudo de caso é entendido como "uma investigação empírica que investiga um fenômeno contemporâneo (o "caso") em profundidade e em seu contexto de mundo real, especialmente quando os limites entre o fenômeno e o contexto puderem não ser claramente evidentes." (YIN, 2015, p. 17).

É importante destacar que esse caso não foi escolhido com base em critérios de pesquisa previamente estabelecidos. Em razão de sua peculiaridade, foi apenas ao se depararem com o programa de VHC da DNDi que os autores decidiram estudá-lo mais profundamente. Esse interesse se deu, preliminarmente, pela possibilidade de se estudar um programa de inovação farmacêutica que trabalhava com dois medicamentos distintos, os quais eram afetados diferentemente pelo sistema de propriedade intelectual vigente. Além disso, chamou a atenção a gravidade da hepatite C para o mundo e como a operacionalização de um mesmo sistema poderia ampliar ou obstruir o acesso a tratamentos acessíveis para essa enfermidade - justificando, com base nos interesses de saúde pública, uma investigação mais detida sobre o tema.

Assim, apesar de ter havido um conjunto de razões que justificou a investigação mais aprofundada do caso selecionado, pode-se afirmar que esta pesquisa foi prevalentemente construída de maneira indutiva. Em outras palavras, no âmbito do presente estudo, não se faz necessária uma hipótese previamente estabelecida, sendo o seu objetivo principal, a partir da análise do corpus empírico selecionado, o de formular afirmações que possam ser testadas em investigações futuras (MACHADO, 2017).

Dessa forma, o presente trabalho será composto por três elementos principais: a contextualização, a descrição e a análise do caso selecionado. Com base na estratégia analítica adotada e com a intenção de facilitar a leitura do trabalho, optou-se por inserir a contextualização do caso ao longo do texto, sempre que necessária. Essa contextualização poderá ser encontrada na introdução, na descrição do caso e, sobretudo, durante a análise realizada.

Nesse sentido, na próxima seção, o caso será descrito com base, principalmente, no relatório "Uma abordagem de saúde pública para a epidemia de hepatite C", da Drugs for neglected diseases initiative (2018b), e nos trabalhos referenciados por ele. Trata-se de um documento confiável, atualizado e produzido pela própria DNDi, o que justificou a sua escolha como fonte principal da pesquisa realizada sobre o caso em estudo. No entanto, por mobilizar elementos bastante dinâmicos e atuais, foi necessário adotar esse documento também como delimitação temporal do caso estudado.

\footnotetext{
5 Unidade única de análise (YIN, 2015).
} 
Em outras palavras, mesmo que tenha havido ocorrências importantes relacionadas ao programa de VHC da DNDi após a publicação desse relatório, elas não serão analisadas no âmbito desse trabalho.

Por fim, após a descrição detalhada do programa de VHC da DNDi e de sua relação com o sistema de propriedade intelectual vigente, proceder-se-á a uma análise detida do caso. Essa análise contará com fontes complementares de dados e com formulações teóricas sobre o assunto. O marco teórico principal da análise será constituído pela perspectiva morfogenética do sistema de propriedade intelectual, adotado por Sell (2003). Segundo este entendimento, o sistema de propriedade intelectual é organizado a partir de estruturas, instituições e agentes que interagem mutuamente em um processo histórico de disputa social. Nesse contexto, as instituições ocupam uma posição central e dinâmica de mediação, que pode se dar em duas direções distintas: ao mesmo tempo em que as estruturas modificam as instituições e criam novos agentes, os próprios agentes podem formular alterações institucionais capazes de criar novas estruturas para o sistema (SELL, 2003).

\section{Programa de VHC da DNDi: a busca de um tratamento pangenotípico, simples e acessível}

O Programa deVHC da DNDise apoia em três pilares principais: pesquisa e desenvolvimento, acesso e modelos de atendimento. No que se refere à pesquisa e desenvolvimento, primeiro pilar do programa, a DNDi estabelece parcerias com companhias farmacêuticas dedicadas a facilitar o acesso para pesquisar e desenvolver candidatos a fármacos promissores, de maneira a possibilitar tratamentos pangenotípicos, simples e acessíveis. Em relação ao acesso, segundo pilar do programa, a DNDi atua para promover mudanças nas políticas públicas, bem como fomentar a vontade política necessária para ampliar o acesso a $\mathrm{AAD}$ pangenotípicos de baixo custo, sobretudo, pela remoção de barreiras regulatórias e de propriedade intelectual. No que diz respeito aos modelos de atendimento, terceiro pilar do programa, a DNDi trabalha com profissionais de saúde para desenvolver modelos de cuidado simples e inovadores, fundamentais para levar o tratamento aos milhões de pessoas que dele necessitam (DRUGS FOR NEGLECTED DISEASES INITIATIVE, 2018b).

Em um primeiro momento, o programa de VHC da DNDi realizou uma análise dos projetos em andamento para encontrar compostos em estágio avançado de desenvolvimento clínico que estivessem de acordo com uma abordagem de saúde pública. A partir dessa análise, a instituição identificou o ravidasvir (RDV), um candidato a fármaco inibidor da proteína não estrutural 5A (NS5A, sigla em inglês) desenvolvido pela companhia biofarmacêutica Presidio Pharmaceuticals (Presidio), da Califórnia, EUA. Em 2015, foram publicados dados referentes a testes clínicos de Fase III (estudos de implementação, em maior escala) conduzidos no Egito pela fabricante de genéricos Pharco Pharmaceuticals (Pharco), os quais revelaram que a combinação sofosbuvir/ravidasvir (SOF/RDV) atingiu uma taxa de cura de 100\% em 170 pacientes GT4 não cirróticos e de 94\% em 130 pacientes GT4 cirróticos (DRUGS FOR NEGLECTED DISEASES INITIATIVE, 2018b; ESMAT et al., 2017). 
Em 2016, com o intuito de acelerar o desenvolvimento do RDV como parte de um regime pangenotípico, simples e acessível, a DNDi realizou um acordo de licença ${ }^{6}$ para países de média e baixa renda e um acordo com a Pharco para garantir o fornecimento clínico de RDV e SOF genéricos (DRUGS FOR NEGLECTED DISEASES INITIATIVE, 2016). Além disso, a instituição lançou um programa de pesquisa e desenvolvimento conhecido pela sigla STORM-C (traduzida como Transformação Estratégica do Mercado de Tratamentos de Hepatite C), com o objetivo de avaliar a eficácia, a segurança, a tolerância e a farmacocinética da combinação RDV/SOF (DRUGS FOR NEGLECTED DISEASES INITIATIVE, 2018b). O primeiro teste clínico, STORM-C-1, teve início na Malásia em 2016 e na Tailândia em 2017, com apoio dos governos dos respectivos países (DRUGS FOR NEGLECTED DISEASES INITIATIVE, 2016).

De acordo com a DNDi, tendo em vista a alta prevalência de VHC, os programas bem estabelecidos de controle dessa doença e a capacidade de expansão desses controles, a Malásia e a Tailândia foram considerados os parceiros ideais e, por isso, foram escolhidos nessa fase inicial do programa. Além disso, na época, também foi determinante o fato de esses dois países terem sido excluídos dos contratos de licenças voluntárias para $\mathrm{AAD}$ e os altos preços exigidos pelas sociedades empresárias titulares das patentes (DRUGS FOR NEGLECTED DISEASES INITIATIVE, 2018b).

No primeiro estágio do STORM-C-1, 301 pacientes, com e sem coinfecção por VIH, foram recrutados com diversos níveis de fibrose hepática e diversos genótipos. No âmbito desse teste, pois, "os pacientes sem cirrose hepática foram tratados com a combinação RDV/SOF durante 12 semanas, e aqueles com cirrose compensada, durante 24 semanas. A maioria dos participantes tinha o genótipo 1 (42\%) ou o genótipo 3 (53\%)." (DRUGS FOR NEGLECTED DISEASES INITIATIVE, 2018b, p. 7).

Em 2018, em consonância com os padrões estabelecidos internacionalmente que definem a cura para tratamento de VHC, os resultados iniciais do estudo clínico STORM-C-1 foram apresentados: 12 semanas após a conclusão do tratamento, 97\% dos participantes estavam curados (IC 95\%: 94,4 98,6) e não foi detectado nenhum sinal inesperado de segurança (ANDRIEUX-MEYER et al., 2018). Segundo a DNDi, esses resultados sugerem que a combinação RDV/SOF é comparável às melhores terapias atuais para a hepatite $\mathrm{C}$ e tem o potencial de atender às três condições necessárias para permitir uma abordagem de saúde pública: um regime de tratamento que seja pangenotípico, simples e acessível (DRUGS FOR NEGLECTED DISEASES INITIATIVE, 2018b).

\footnotetext{
6 De acordo com o art. 28 (2), do Acordo sobre Aspectos dos Direitos de Propriedade Intelectual Relacionados ao Comércio (TRIPS, sigla em inglês), "os titulares de patente terão também o direito de cedê-la ou transferi-la por sucessão e o de efetuar contratos de licença." (WORLD TRADE ORGANIZATION, 1994). Ao longo do texto, esta modalidade de licença será também referenciada como licença voluntária, em contraposição à licença compulsória, que é regulamentada pelo art. 31 , do TRIPS (WORLD TRADE ORGANIZATION, 1994).
} 


\subsection{Pangenotípico}

Por serem comprovadamente efetivos contra todos os seis genótipos do VHC, os regimes pangenotípicos são fundamentais para a concretização de uma estratégia de saúde pública de enfrentamento dessa doença. Essa característica é um componente importante para eliminar a necessidade e o custo considerável de testes de genótipo pré-tratamento, para simplificar a compra e a entrega do tratamento e, por fim, para facilitar a criação e a expansão de programas de diagnóstico. No entanto, até maio de 2018, dos 13 AAD e das várias combinações de AAD com doses fixas aprovados pela Food and Drug Administration (FDA) e pela Agência Europeia de Medicamentos (AEM), apenas 4 regimes aprovados podem ser considerados pangenotípicos (WORLD HEALTH ORGANIZATION, 2018a). Além disso, é importante destacar que, dentre esses poucos regimes pangenotípicos, todos possuem limitações em termos de acesso em países de média e baixa renda (DRUGS FOR NEGLECTED DISEASES INITIATIVE, 2018b).

O primeiro regime, sofosbuvir/velpatasvir (SOF/VEL), fabricado pela Gilead Sciences Inc. (Gilead), possui o uso registrado em poucos países em desenvolvimento e, no total, somente cerca de 20 países estão em processo de registro (GILEAD SCIENCES INC., 2017 apud DRUGS FOR NEGLECTED DISEASES INITIATIVE, 2018b). O segundo, sofosbuvir/velpatasvir/voxilaprevir, também fabricado pela Gilead, está registrado somente para pessoas com VHC que já se tratam com um regime de $\mathrm{AAD}$ sem sucesso, não podendo ser considerado, portanto, um tratamento de primeira linha (CENTER FOR DRUG EVALUATION AND RESEARCH, 2017; DRUGS FOR NEGLECTED DISEASES INITIATIVE, 2018b). O terceiro regime, glecaprevir/pibrentasvir, fabricado pela Abbvie, ainda não teve anunciado um programa de acesso para países de média e baixa renda (DRUGS FOR NEGLECTED DISEASES INITIATIVE, 2018b). E, por fim, no que diz respeito ao quarto regime, sofosbuvir/daclatasvir (SOF/DCV), ${ }^{8}$ destaca-se que não há ainda uma fonte genérica de DCV préqualificada pela OMS, de modo que os países não possuem uma garantia dessa organização (DRUGS FOR NEGLECTED DISEASES INITIATIVE, 2018b; WORLD HEALTH ORGANIZATION, 2019).

\footnotetext{
Apesar de ter sido esclarecido previamente, na seção dedicada à metodologia, que o relatório da Drugs for Neglected Diseases Initiative (2018b) seria utilizado como marco temporal da descrição dos fatos relacionados ao presente estudo de caso, não foi possível acessar e conferir o documento referenciado pela entidade sobre o registro da combinação SOF/VEL, fabricado pela Gilead. O documento citado pela DNDi não está mais disponível na internet e parece ter sido atualizado. Assim sendo, de acordo com o documento publicado pela Gilead, em junho de 2019, essa combinação em dose fixa, vendido sob a denominação Epclusa, tem seu uso registrado em 23 países em desenvolvimento e está em processo de registro em outros 7 (GILEAD SCIENCES INC., 2019).

8 Embora não seja classificada como pangenotípica pelas diretrizes de tratamento mais recentes da Associação Europeia para o Estudo do Fígado (EASL, sigla em inglês) e da Associação Americana para o Estudo das Doenças do Fígado (AASLD, sigla em inglês) (DRUGS FOR NEGLECTED DISEASES INITIATIVE, 2018b; EUROPEAN ASSOCIATION FOR THE STUDY OF THE LIVER, 2018), o perfil pangenotípico da combinação SOF/DCV é confirmado pelas recomendações da OMS publicadas em julho de 2018 (WORLD HEALTH ORGANIZATION, 2018a). De acordo com a DNDi, essa decisão deve ser bem recebida, uma vez que este "é o tratamento mais comum em PMBR [países de média e baixa renda] e pode exercer um papel fundamental para possibilitar uma abordagem de saúde pública para essa epidemia." (DRUGS FOR NEGLECTED DISEASES INITIATIVE, 2018b, p. 8).
} 
Por sua vez, os testes realizados no âmbito do programa de pesquisa e desenvolvimento da DNDi, STORM-C-1, com a combinação RDV/SOF, fornecem dados in vitro de todos os genótipos e dados in vivo predominantemente dos genótipos 1, 3, 4 e 6. Além disso, quando se analisa apenas o GT3, que possui uma ampla disseminação geográfica e é considerado um dos genótipos mais difíceis de tratar, as taxas de cura são equivalentes aos melhores $\mathrm{AAD}$ disponíveis no mercado: dos pacientes participantes com GT3, 97\% foi curado e 96\% daqueles que têm GT3 e cirrose hepática avançada também foi curado (DRUGS FOR NEGLECTED DISEASES INITIATIVE, 2018b).

Esses resultados promissores nos casos mais difíceis de tratar são fundamentais para que a combinação RDV/SOF possa ser utilizada em uma estratégia de saúde pública, uma vez que muitos $\mathrm{AAD}$ fazem parte da mesma classe de fármacos e o tratamento malsucedido com qualquer um deles poderia induzir resistência a todos os outros fármacos da mesma classe. Em outras palavras, tendo em vista que o conjunto de recursos para o tratamento do VHC exige múltiplas opções terapêuticas, as taxas de cura consideravelmente altas da combinação RDV/SOF apresenta um risco menor de induzir resistência a todos os fármacos NS5A e evita disseminação de linhagens resistentes da doença (DRUGS FOR NEGLECTED DISEASES INITIATIVE, 2018b).

\subsection{Simples}

No âmbito de uma estratégia de saúde pública, não basta que o regime seja pangenotípico, é necessário também que ele seja simples - efetivo para todas as pessoas, incluindo os pacientes mais difíceis de tratar. Nesse caso específico, dentre as pessoas infectadas com o VHC, deve-se ter em conta as dificuldades especiais em torno de pacientes que possuem o GT3, doenças do fígado e cirrose hepática avançada, bem como dos usuários de drogas injetáveis ativos, das pessoas em terapia de substituição de opioides e daqueles que já passaram por um tratamento de VHC sem sucesso. Além disso, para ser considerado simples, um regime deve ser seguro e facilmente utilizável para pacientes com outras doenças, sobretudo, aqueles coinfectados com VIH e VHC (DRUGS FOR NEGLECTED DISEASES INITIATIVE, 2018b).

Por meio da aplicação das lições aprendidas com a expansão bem-sucedida do tratamento do VIH, um regime simples possibilita que os profissionais de saúde alcancem milhões de pessoas em situação de baixos recursos. Pode-se destacar, entre essas estratégias de simplificação, a transferência de tarefas e o acompanhamento de casos não complexos dos médicos para os enfermeiros, tal qual a simplificação dos algoritmos de diagnóstico e outras ferramentas para reduzir a perda de pacientes no acompanhamento da chamada "cascata de tratamento". Exemplo disso seria a descentralização do diagnóstico e do tratamento para todos os níveis do sistema de saúde (DRUGS FOR NEGLECTED DISEASES INITIATIVE, 2018b).

As dificuldades enfrentadas pelos profissionais da saúde já tornam evidente a necessidade de regimes simples. Em 2016, por exemplo, os Médicos Sem Fronteiras (MSF) inauguraram um 
programa de tratamento de VHC em um hospital de 250 leitos, na cidade Phnom Penh, no Camboja. Nessa ocasião, a clínica ficou sobrecarregada em poucos meses e os MSF apontaram a necessidade de exames laboratoriais complexos e a alta quantidade de consultas de acompanhamento como os principais obstáculos para o atendimento de um número maior de pacientes (DRUGS FOR NEGLECTED DISEASES INITIATIVE, 2018b; IWAMOTO et al., 2017).

Assim, os resultados do estudo STORM-C-1 passam a ter grande importância, uma vez que "a boa tolerabilidade e a ausência de sinais de segurança, mesmo em pacientes com múltiplas comorbidades, indicam que o perfil de segurança do RDV/SOF favorece a simplificação e a transferência de tarefas no modelo de assistência para VHC." (DRUGS FOR NEGLECTED DISEASES INITIATIVE, 2018b, p. 9). Nesse sentido, destaca-se, principalmente, o excelente desempenho desse tratamento em pacientes coinfectados com VIH/VHC, que obteve taxas de cura muito altas (97\%). E, além disso, a confirmação do perfil farmacológico favorável do RDV, que não revelou interações farmacológicas clinicamente significativas com os fármacos antirretrovirais mais comuns no tratamento do VIH (CRESSEY et al., 2018; DRUGS FOR NEGLECTED DISEASES INITIATIVE, 2018b). Ademais, ainda no que tange à simplicidade do regime em análise, outros resultados do estudo STORM-C-1 merecem ser destacados, como a "alta eficácia em pacientes com doenças do fígado e cirróticos (96\% de cura), pessoas que já haviam passado por tratamentos de VHC (96\%) ede particular importância - também de pessoas que combinavam vários fatores de risco." (DRUGS FOR NEGLECTED DISEASES INITIATIVE, 2018b, p. 9).

\subsection{Acessível}

A acessibilidade aos tratamentos para VHC ainda é um dos maiores problemas a serem enfrentados, assim como um grande desafio para a saúde pública na maioria dos países. O SOF, por exemplo, ao ser lançado, nos EUA, a US\$ 1 mil por comprimido, tornou-se um símbolo dos altos preços impostos pelos monopólios patentários e da obstrução à fabricação de medicamentos genéricos mais acessíveis. O tratamento completo custava US\$ 84 mil, sem incluir o custo com outros medicamentos. Dessa forma, no início, como os outros $\mathrm{AAD}$ possuíam preços parecidos, em diversos países, a nova geração de tratamentos para VHC foi reservada apenas para os pacientes em estado mais grave (DRUGS FOR NEGLECTED DISEASES INITIATIVE, 2018b).

Passados os primeiros anos de mercado, houve uma queda considerável de preços em alguns países. Em 2017, entre os preços genéricos mais baixos informados à OMS, está o tratamento de três meses com a combinação SOF/VEL, por US\$375. Além disso, também em 2017, uma licitação dos MSF alcançou o preço de US\$ 120 por um tratamento de três meses com a combinação SOF/DCV (MÉDECINS SANS FRONTIÈRES, 2017). O resultado desta licitação realizada pelos MSF, de acordo com DNDi, pode servir de referência para países que visam a alcançar preços mais baixos para o tratamento para VHC (DRUGS FOR NEGLECTED DISEASES INITIATIVE, 2018b). 
No entanto, apesar da redução considerável de preços, a crise de acessibilidade parece estar longe de ser solucionada, dado que os preços dos tratamentos disponíveis para VHC permanecem altos e obstruem políticas públicas importantes. Os custos elevados tanto impedem os países de implantarem estratégias de identificação de pessoas assintomáticas que vivem com a doença, quanto prejudicam a elaboração de estratégias de "diagnóstico e tratamento" capazes de eliminar o VHC. Destaca-se, pois, que a maioria das pessoas que vivem com VHC em todo o mundo ainda não foi diagnosticada e não tem acesso ao tratamento (DRUGS FOR NEGLECTED DISEASES INITIATIVE, 2018b).

Sobretudo os países nos quais foram pedidas ou concedidas patentes para $\mathrm{AAD}$ e que foram excluídos de contratos de licença voluntária, os custos permanecem muito elevados. Esse cenário pode ser observado com precisão na realidade dos países de renda média, os quais costumam ser excluídos dos contratos de licença por não serem pobres o suficiente para se qualificarem para obter preços de medicamentos genéricos, nem ricos o suficiente para poderem pagar os valores exorbitantes cobrados pelas empresas originárias (DRUGS FOR NEGLECTED DISEASES INITIATIVE, 2018b). Dentre os países que estão incluídos nessa situação, podem ser citados o Brasil, a China, a Colômbia, o Cazaquistão, o México e a Turquia, que, juntos, possuem cerca de 14 milhões de pessoas que vivem com a infecção de VHC. De acordo com a OMS, 38\% das pessoas infectadas por VHC no mundo estão excluídas do acesso a um tratamento econômico (WORLD HEALTH ORGANIZATION, 2018b).

Diante desse contexto, a estratégia estabelecida pela DNDi contrasta intensamente com o modelo tradicional de desenvolvimento de novos tratamentos para VHC, visto que a política da instituição não é movida pela lógica lucrativa, mas, primordialmente, pelo objetivo de disponibilizar tratamentos acessíveis para a população necessitada. Ao mesmo tempo que a DNDi conseguiu obter uma entidade química completamente nova de uma empresa originária, por meio de colaborações e contratos de sublicença, conseguiu também garantir preços acessíveis desde o início (DRUGS FOR NEGLECTED DISEASES INITIATIVE, 2018b).

Na Malásia, por exemplo, a Pharco firmou o compromisso de fornecer a combinação RDV/ SOF, quando for aprovada, por US\$300 ou menos por tratamento para o programa de tratamento nacional (DRUGS FOR NEGLECTED DISEASES INITIATIVE, 2016). Esse compromisso representa uma redução de mais de 100 vezes em relação ao preço praticado pela empresa originária do tratamento previamente existente no país, o que chega a ser mais de US\$ 75 mil para SOF/DCV (FONG, 2018) ou US\$ 33 mil somente para SOF (DRUGS FOR NEGLECTED DISEASES INITIATIVE, 2018b; WORLD HEALTH ORGANIZATION, 2018b).

$\mathrm{Na}$ América Latina, em conjunto com as sociedades empresárias Insud Pharma e Laboratorio Elea Phoenix, da Argentina, a DNDi estabeleceu parcerias não só para tentar registrar o RDV, mas também para fabricar e distribuir o RDV e o SOF genéricos em toda a região (DRUGS FOR NEGLECTED DISEASES INITIATIVE, 2018a). Mesmo que o custo de produção do RDV seja potencialmente maior que outros $\mathrm{AAD}$, graças aos compromissos celebrados, a meta dessa parceria é de que o tratamento seja disponibilizado por um preço inferior a US\$ 500. Além disso, com o 
registro e com o lançamento do RDV em vários países, a DNDi estima que o aumento do volume de vendas ajude ainda mais na redução dos preços praticados no mercado, podendo-se atingir a marca de US\$ 300 (DRUGS FOR NEGLECTED DISEASES INITIATIVE, 2018b). Vale destacar que os custos esperados por essa inciativa são significativamente inferiores em comparação aos tratamentos já existentes na região: na Argentina, o tratamento de 12 semanas para Hepatite C custa, no mínimo, US\$ 7 mil; no Chile, custa US\$ 12 mil; e, no Brasil, mais de US\$ 6 mil (DRUGS FOR NEGLECTED DISEASES INITIATIVE, 2018a). Em 2018, na região, o melhor preço para um regime pangenotípico era de US\$ 4,5 mil, obtido por meio da Organização Pan-Americana da Saúde (MSF ACCESS CAMPAIGN, 2018).

\subsection{O programa de VHC da DNDi e o sistema de propriedade intelectual}

As patentes relacionadas ao RDV são de propriedade da companhia biofarmacêutica Presidio, sediada na Califórnia, nos EUA, da qual a DNDi obteve direitos de licença não exclusivos para países de média e baixa renda e com a qual a DNDi também tem a opção de negociar os direitos de licença para outros países de renda alta.

Paralelamente, de modo a abrir a possibilidade de concorrência de medicamentos genéricos em diversos países que não se encontravam contemplados pelas licenças da DNDi, a maior companhia biofarmacêutica do Egito, a Pharco, sublicenciou os direitos sobre o RDV para o Pool de Patentes de Medicamentos (MPP, sigla em inglês). Essa iniciativa passou a abranger "países de baixa e média renda, incluídos países com altos níveis de prevalência, como a Rússia, a Ucrânia, o Egito e o Irã." (MEDICINES PATENT POOL, 2017, p. 1). Além disso, destaca-se que, apesar de a licença celebrada entre MPP e Pharco para o ravidasvir incluir royalties sobre as vendas líquidas nos territórios licenciados - 4\% nos países de renda baixa e 7\% nos países de renda média -, a Pharco renunciou ao seu direito aos royalties relacionados às formulações pediátricas; e a licença inclui a transferência de tecnologia aos sublicenciados do MPP (MEDICINES PATENT POOL, 2017).

No que se refere à China, Hong Kong e Taiwan, os direitos de propriedade intelectual pertencem à companhia biofarmacêutica chinesa Ascletis, que, em 2014, assinou um contrato de licença exclusiva com a Presidio, por um valor de US\$17 milhões, mais royalties baseados nas vendas líquidas da companhia. Nessa região há também problemas graves com o VHC: na China, por exemplo, a hepatite C é uma das principais causas de doenças crônicas no fígado, como a cirrose e o câncer, de modo que, em 2017, cerca de 1,82\% da população estava infectada. Além disso, apesar de cerca de 350 mil novas infecções tenham sido registradas em 2017, somente cerca de 74 mil pacientes foram tratados por conta da falta de novos tratamentos (NG, 2018).

De acordo com o diretor executivo da Unitaid - entidade que financia o MPP -, Lelio Mármora, "os esforços combinados do MPP, da DNDi e dos parceiros do setor privado mostram como se pode aproveitar as atividades de pesquisa e desenvolvimento e as licenças para se encontrarem 
soluções positivas para a saúde." (MEDICINES PATENT POOL, 2017, p. 1, tradução livre). Com efeito, ao serem combinados, os acordos da DNDi e do MPP teriam o potencial de gerar benefícios para os países das 139 economias classificadas como de baixa e média renda pelo Banco Mundial, nos quais habitam 85,3\% das pessoas infectadas pelo VHC (MEDICINES PATENT POOL, 2017).

Por outro lado, embora os direitos de propriedade intelectual relacionados ao RDV tenham sido compartilhados de uma maneira inovadora e tenham sido gerenciados de modo a promover o acesso deste medicamento para populações necessitadas, a mesma situação não pode ser verificada no caso do SOF. Apesar de ser considerado a espinha dorsal dos tratamentos de AAD atuais, inclusive do regime proposto pelo programa de VHC da DNDi, o acesso a este medicamento continua sendo bastante dificultado por restrições impostas pelo monopólio patentário (DRUGS FOR NEGLECTED DISEASES INITIATIVE, 2018b).

Em2014, oSOF foi descoberto pelo bioquímico Raymond Shiniazi, professor da Universidade de Emory, nos EUA, no âmbito de seu projeto acadêmico financiado pelos Institutos Nacionais de Saúde dos EUA (NIH, sigla em inglês) e pelo Departamento de Assuntos de Veteranos dos EUA. Dez anos antes, em 2004, Shiniazi havia ajudado a construir uma companhia biofarmacêutica chamada Pharmasset Inc., que investiu cerca de US\$ 62,4 milhões na P\&D do SOF, antes de vendê-lo para a Gilead, por US\$ 11,2 bilhões, em $2012^{9}$ (COSTANTINI; WALENSKY, 2019). Como as projeções de mercado para a nova classe de medicamentos para hepatite $C$ indicavam a marca de US\$20 bilhões por ano, em 2020, a Gilead estava disposta a pagar um alto valor para se antecipar nesse cenário altamente lucrativo, antes que outros concorrentes ingressassem no mercado (TIRRELL, 2014).

Apesar de a companhia não ter desempenhado um grande papel no desenvolvimento do SOF, ela mais que dobrou o valor comercial que havia sido planejado inicialmente pela Pharmasset - US\$ 36 mil - e fixou o preço do tratamento de 12 semanas para hepatite C em US\$ 84 mil, equivalente a US\$ 1 mil por pílula ${ }^{10}$ (HATCH, WYDEN, 2015). Em comparação, o preço do SOF, em outros países desenvolvidos, variava entre US\$ 53 mil (Reino Unido) e US\$ 28 mil (Portugal) e, em 101 países considerados de média e baixa renda, poderia ser encontrado por US\$ 900 (GILEAD SCIENCES INC., 2015; HILL et al., 2016).

Apesar dos altos valores fixados pela Gilead, há uma estimativa de que o custo para desenvolver o mesmo tratamento variaria entre US\$68 e US\$136, o que significaria, a proximadamente, US\$1,62 por pílula (HILL et al., 2016). Dessa forma, o preço deste medicamento não parece ter sido baseado em seus custos de inovação e de produção, mas sim no preço máximo que o público e as organizações privadas aceitariam pagar por ele, como ressaltam Cassier e Correa (2019).

\footnotetext{
9 Os testes clínicos de fase II do SOF foram financiados pela NIH e os testes clínicos de fase III foram financiados pela Gilead. Embora não tenha sido revelado pela sociedade empresária, estima-se que o investimento realizado pela Gilead, na fase III, tenha sido entre US\$ 50 milhões e US\$ 100 milhões (COSTANTINI; WALENSKY, 2019).

${ }^{10}$ De acordo com o relatório dos Médecins Sans Frontières (2016), ao se comparar o preço por grama, o SOF, na data de seu lançamento no mercado estadunidense, era quase 67 vezes mais caro que o ouro.
} 
Além disso, a Gilead anunciou uma política de licenças voluntárias para 11 produtores indianos de medicamentos genéricos, autorizando-os a produzir o SOF genérico e exportá-lo somente aos mesmos 101 países de média e baixa renda - nos quais a sociedade empresária já praticava preços reduzidos - em troca do pagamento de 7\% de royalties (GILEAD SCIENCES INC., 2015; GILEAD SCIENCES INC., 2014; HILL et al., 2016). Essa estratégia de precificação e licenciamento adotada pela Gilead, apesar de veicular publicamente a intenção de ampliar o acesso ao SOF, foi acusada de, na verdade, obstruir a competição no mercado de genéricos (INTERNATIONAL TREATMENT PREPAREDNESS COALITION, 2015).

A lista de 101 países definidos pela Gilead incluía principalmente os países de renda baixa e os países menos desenvolvidos, com apenas poucos países de renda média. Dessa forma, a política de acesso formulada pela sociedade empresária excluía 51 importantes países de renda média que possuem uma grande prevalência de hepatite C, como a China, o Brasil, as Filipinas, a Turquia, a Tailândia e o México - que, juntos, totalizam mais de 38,5 milhões de pessoas infectadas. Essa iniciativa teria pouca chance, portanto, de ampliar o acesso ao tratamento de VHC, já que, ao contrário do VIH, a maior carga dessa doença é suportada por países de média e alta renda, onde habitam 73\% dos 185 milhões de pessoas infectadas em todo o mundo (INTERNATIONAL TREATMENT PREPAREDNESS COALITION, 2015).

De acordo com a diretora executiva da organização International Treatment Preparedness Coalition (ITPC), Christine Stegling, considerando a ausência de um mecanismo global de financiamento do tratamento para VHC nos países mais pobres, seria muito improvável que esse conjunto de licenças tivesse algum impacto significativo. Segundo ela, a política de licenciamento voluntário da Gilead não inclui países em desenvolvimento que têm mostrado liderança na implementação de programas de tratamento e no investimento de recursos próprios no tratamento da sua população. Assim, essas licenças voluntárias podem ter grandes limitações, porquanto nem sempre são capazes de promover a produção e a exportação dos medicamentos genéricos (INTERNATIONAL TREATMENT PREPAREDNESS COALITION, 2015).

Além disso, ainda de acordo com Stegling, tendo em vista que as sociedades empresárias originadoras frequentemente não registram seus respectivos produtos nos países mais pobres, isso poderia significar, no final das contas, um impeditivo para os produtores de medicamentos genéricos que quisessem registrar seus produtos nesses países. Nesse sentido, Stegling destaca que, no caso em tela, a Gilead ainda não teria disponibilizado nenhum cronograma de registro do SOF nos países previamente selecionados por ela (INTERNATIONAL TREATMENT PREPAREDNESS COALITION, 2015).

De qualquer forma, mesmo que não estejam claros os impactos nos países contemplados pela política de licenciamento voluntário da Gilead, argumenta-se que essa estratégia bloquearia imediatamente o acesso a medicamentos genéricos nos países excluídos, mesmo que não existam barreiras patentárias. Ademais, dado o grande número de pessoas infectadas pelo VHC em 
seus territórios, esses países - presentes nas regiões da América Latina, do Norte da África, do Oriente Médio, do Leste Europeu e da Ásia - não poderiam arcar com os altos preços impostos pela Gilead e nem mesmo com os seus preços reduzidos, ficando completamente impedidos de implantar programas efetivos de tratamento para suas respectivas populações (INTERNATIONAL TREATMENT PREPAREDNESS COALITION, 2015; MÉDECINS SANS FRONTIÈRES, 2016).

É importante destacar, ainda, que, entre os territórios licenciados pela Gilead, estão alguns países considerados menos desenvolvidos, que têm até 2021 para implementar o Acordo sobre Aspectos dos Direitos de Propriedade Intelectual Relacionados ao Comércio (TRIPS, sigla em inglês) e, por isso, ainda não estariam obrigados a conceder patentes. Além disso, as licenças voluntárias negociadas pela sociedade empresária também fornecem as condições para monopólios de mercado nos países excluídos, onde a Gilead não possui patentes e nem o direito de requerer um monopólio (INTERNATIONAL TREATMENT PREPAREDNESS COALITION, 2015).

De acordo com Tahir Amin, Diretor de Propriedade Intelectual da I-MAK, instituição que tem protocolado oposições ao registro do SOF na Índia, não existem patentes deste medicamento na Índia e em vários outros países nos quais as fabricantes de medicamentos genéricos estariam autorizadas a comercializar seus produtos. Segundo ele, essas licenças possuem claramente o objetivo de obstruir a concorrência, deixando milhões de pessoas necessitadas sem o acesso a este medicamento, pois existe uma grande probabilidade de que os pedidos de patente da Gilead sejam indeferidos ao redor do mundo e, mesmo assim, a estratégia de licenciamento da companhia impediria as fabricantes de medicamentos genéricos de comercializar o SOF nesses mesmos países (INTERNATIONAL TREATMENT PREPAREDNESS COALITION, 2015).

Outro ponto de preocupação deriva do fato de que a estratégia de licenciamento voluntário da Gilead também exclui a venda de insumos farmacêuticos ativos - matéria prima para a produção local do SOF - para quem não seja parceiro da companhia. Essa proibição abarca até mesmo os países inicialmente incluídos pela licença, impedindo-os de produzir seus próprios medicamentos. Segundo Othoman Mellouk, Coordenador Regional de Advocacy do ITPC para o Oriente Médio e Norte da África (MENA, sigla em inglês), em países como o Egito, por exemplo, onde 20 milhões de pessoas são infectadas pelo VHC, os governos não serão capazes de assegurar tratamento para todos, mesmo com o preço reduzido oferecido pela Gilead (INTERNATIONAL TREATMENT PREPAREDNESS COALITION, 2015).

De acordo com Mellouk, embora o país tenha iniciado recentemente os trabalhos para a produção local do SOF para garantir a sustentabilidade do tratamento, com essa política de licenciamento, os fabricantes locais não poderão comprar insumos farmacêuticos ativos dos fornecedores indianos. Dessa forma, o Egito teria que confiar exclusivamente nos produtores de medicamentos genéricos previamente selecionados pela Gilead, significando uma verdadeira substituição de um monopólio por outro. Em outras palavras, em consonância com esse entendimento, em razão da estratégia promovida pela Gilead, mesmo que o país esteja abrangido 
pela licença voluntária e a patente do SOF não tenha sido concedida em seu território, o ambiente não é propício para uma concorrência livre e justa entre produtores de medicamentos genéricos (INTERNATIONAL TREATMENT PREPAREDNESS COALITION, 2015).

Esse entendimento parece ser corroborado por Marcela Vieira, coordenadora do Grupo de Trabalho em Propriedade Intelectual (GTPI/Rebrip), ao afirmar que, apesar de a Gilead ter anunciado seus acordos de licenciamento como um meio de fomentar o acesso ao SOF nos países em desenvolvimento, está claro que a verdadeira intenção da companhia foi a de segmentar os mercados e maximizar os seus próprios lucros (INTERNATIONAL TREATMENT PREPAREDNESS COALITION, 2015).

Sendo assim, desde o lançamento do SOF no mercado e a implementação da estratégia de licenciamento da Gilead, as pressões geradas pela mídia, a crise financeira e as necessidades de saúde pública levaram o Comitê de Finanças do Senado Americano a publicar, em 2015, um relatório capaz de demonstrar a relevância global do tema e também a importância da concorrência no setor farmacêutico. De acordo com esse estudo, durante o ano de 2014, US\$1,3 bilhões haviam sido gastos com o SOF, com o tratamento de apenas 2,4\% dos infectados por VHC inscritos no programa governamental Medicaid. E, além disso, à medida que novos concorrentes têm entrado no mercado estadunidense com outros tratamentos para a Hepatite C, também foi possível constatar uma correspondente redução de preços nos tratamentos disponíveis para a doença (HATCH; WYDEN, 2015).

\section{Análise do caso}

Em um primeiro momento, ao se analisar o caso em estudo, chamam a atenção os preços exorbitantes cobrados pelo SOF, as suas variações ao redor do mundo e, consequentemente, os seus efeitos prejudiciais para o acesso da população infectada pelo VHC a este medicamento. Além disso, como o SOF é considerado um componente fundamental dos tratamentos de AAD atuais, notase que, mesmo que a DNDi e seus parceiros tenham se esforçado para estabelecer estratégias que maximizassem o acesso ao RDV, as barreiras impostas pela estratégia adotada pela Gilead continuam sendo determinantes para a exclusão das populações mais necessitadas ao tratamento completo desenvolvido para combater a hepatite C.

Como se pôde observar acima, atualmente, os altos preços de medicamentos estão diretamente relacionados aos monopólios patentários e são um assunto preocupante em todo o mundo, desde países de baixa renda até países de alta renda, como os EUA (COSTANTINI; WALENSKY, 2019; MÉDECINS SANS FRONTIÈRES, 2016). As patentes farmacêuticas, até a sua data de expiração, dão aos seus titulares, geralmente companhias farmacêuticas, direitos 
exclusivos para fabricar, vender e fixar o preço de seus respectivos produtos sem se preocupar com a concorrência ${ }^{11}$ (MÉDECINS SANS FRONTIÈRES, 2016).

Esse sistema de monopólio e de preços exorbitantes está ancorado globalmente em uma estrutura internacional de comércio muito bem estabelecida. O acordo TRIPS, de 1994, introduziu um novo sistema vinculante de propriedade intelectual, ao qual todos os países membros da OMC estavam submetidos. De fato, esse acordo passou a ser um elemento determinante para as suas respectivas políticas internas. A implementação desse sistema teria se dado em razão da atuação consistente do setor privado estadunidense, em conjunto com suas contrapartes no Japão e na Europa, contando com uma ativa resistência dos países em desenvolvimento (SELL, 2003).

Assim, nas últimas duas décadas, os países têm sido levados a fortalecer substancialmente esse sistema e até mesmo a implementar novos modelos de proteção patentária, acarretando uma uniformização global flagrantemente contraditória às abordagens plurais existentes antes do TRIPS, quando os países poderiam regulamentar os direitos de patente soberanamente, de acordo com seus próprios contextos e interesses socioeconômicos. Desde então, os mecanismos utilizados para constranger a ampliação do sistema de propriedade intelectual têm sido denominados de TRIPS-plus, que abrangem desde a inclusão unilateral de novas legislações domésticas até os acordos bilaterais e os acordos multilaterais de comércio, como pode ser visto no caso recente do Acordo de Associação Transpacífico (TPP, sigla em inglês), que estabeleceu uma área de livre comércio entre países da Ásia, da Oceania e da América (MÉDECINS SANS FRONTIÈRES, 2016; MSF ACCESS CAMPAIGN, 2018).

A indústria farmacêutica tem sido uma das maiores defensoras da manutenção, do fortalecimento e da expansão dos direitos de propriedade intelectual ao redor do mundo. As sociedades empresárias desse setor costumam alegar que o monopólio patentário e os altos custos dos medicamentos são estritamente necessários não só para recuperar os investimentos realizados em $\mathrm{P} \& \mathrm{D}$, mas também para garantir a viabilidade de investimentos futuros em inovação. Para esses agentes industriais, portanto, quanto maior a proteção dada às patentes, maiores os níveis de inovação farmacêutica (MÉDECINS SANS FRONTIÈRES, 2016; PHARMACEUTICAL RESEARCH AND MANUFACTURERS OF AMERICA, 2019; ZAMPIERI, 2015).

De acordo com os MSF, todavia, existem pelo menos quatro argumentos que fragilizam esse posicionamento. Em primeiro lugar, o crescimento do número de patentes ao redor do mundo não tem sido acompanhado por um aumento equivalente de inovação de produtos médicos. Segundo eles, evidências históricas sugerem que as patentes não são uma condição necessária para a inovação, visto que a ampla maioria das inovações teria ocorrido fora do sistema de patentes e que políticas públicas limitadoras dos direitos patentários, como a licença compulsória, ${ }^{12}$ parecem ter fomentado

\footnotetext{
${ }_{11}$ Não se exclui, todavia, a possibilidade da utilização de outros tipos de propriedade intelectual para obstruir a concorrência no setor farmacêutico, como, por exemplo, o segredo de negócio (MÉDECINS SANS FRONTIÈRES, 2016).

12 As condições para a licença compulsória estão previstas no art. 31, do TRIPS (WORLD TRADE ORGANIZATION, 1994).
} 
diretamente os níveis de inovação ao longo da história (MÉDECINS SANS FRONTIÈRES, 2016; MOSER, 2016).

Em segundo lugar, para os MSF, não é verdade que os lucros obtidos com as vendas de medicamentos estejam sendo reinvestidos em P\&D (COLLIER, 2009; MÉDECINS SANS FRONTIÈRES, 2016; ZAMPIERI, 2015). Segundo eles, em 2010, último ano em que o grupo Pharmaceutical Research Manufacturers of America (PhRMA) publicou as estimativas globais dos gastos em P\&D, as companhias farmacêuticas reportaram investimentos em P\&D abaixo de $8 \%$ do total das vendas globais relacionadas pela IMS Health (LOVE, 2011; MSF, 2016). Com uma metodologia diferente, todavia, um relatório produzido pelos próprios membros da PhRMA coloca os seus investimentos em P\&D em 17,9\% das vendas, em 2014 (MÉDECINS SANS FRONTIÈRES, 2016; PHARMACEUTICAL RESEARCH AND MANUFACTURERS OF AMERICA, 2015).

A organização humanitária, por sua vez, ainda destaca que as cinco maiores companhias farmacêuticas investem US\$ 60 bilhões em marketing, por ano, e somente uma das 10 maiores companhias farmacêuticas do mundo gastam mais em pesquisa do que em marketing (SWANSON, 2015). Entre 2005 e 2014, 19 das maiores sociedades empresárias do setor farmacêutico teriam investido, conjuntamente, US\$226 bilhões na recompra de suas próprias ações, o que equivale a $51 \%$ dos valores investidos em P\&D por todas elas, durante o mesmo período (LAZONICK et al., 2016; MÉDECINS SANS FRONTIÈRES, 2016).

Em terceiro lugar, de acordo com os MSF, a inovação sem o acesso é uma inovação inútil para a sociedade. Para eles, os problemas de acessibilidade gerados pela aposta no patenteamento e na exclusividade de mercado são um obstáculo para a verdadeira inovação farmacêutica, a qual, por ser acessível, teria o poder real de enfrentar os grandes desafios existentes e de contemplar os interesses de saúde pública (MÉDECINS SANS FRONTIÈRES, 2016).

Por fim, em quarto lugar, os MSF afirmam que a fixação de preços não possui qualquer relação com os custos reais de $\mathrm{P} \& \mathrm{D}$ e está diretamente ligada com os valores máximos que o mercado pode suportar. Afinal, é isso o que mostra uma série de grandes aumentos nos preços de medicamentos que já não possuem mais proteção patentária nos EUA. Sociedades empresárias que se tornaram as únicas fornecedoras aprovadas pela FDA de determinados medicamentos exploram suas posições monopolísticas no mercado para aumentar drasticamente o preço de seus produtos. Um caso emblemático desse fenômeno foi protagonizado por Martin Shkreli, que aumentou repentinamente, em $5.500 \%$, o preço de um medicamento de mais de 50 anos, utilizado para o tratamento de infecções relacionadas ao VIH'13 (MÉDECINS SANS FRONTIÈRES, 2016).

Além dos argumentos formulados pelos MSF, outros dados corroboram esse entendimento. Apesar de os altos custos com P\&D serem, geralmente, o principal argumento das companhias

\footnotetext{
${ }^{13}$ Embora parte da indústria farmacêutica tenha repudiado esse comportamento e o caracterizado como uma exceção incapaz de representar a conduta das sociedades empresárias do setor, os Médecins Sans Frontières (2016) trazem vários outros exemplos de condutas semelhantes, desta vez, praticadas por companhias como Novartis, Biogen e Pfizer.
} 
farmacêuticas para justificar os preços elevados de seus produtos (MAXMEN, 2016), os dados revelam que das 5 companhias que mais investiram em P\&D em 2018, nenhuma era do setor farmacêutico. Além disso, nesse mesmo período, somente 6 companhias farmacêuticas figuraram entre as 20 companhias que mais investiram em P\&D em todo o mundo, com investimentos em torno de US\$ 6 bilhões a US\$ 11 bilhões (STATISTA, 2019).

Complementarmente, enquanto a margem estimada de lucro das sociedades empresárias de outros setores industriais variou entre 4\% e 9\%, entre 2006 e 2015, a margem de lucro da indústria farmacêutica variou entre 15\% e 20\%, no mesmo período (UNITED STATES GOVERNMENT ACCOUNTABILITY OFFICE, 2017). Esses dados parecem, de fato, fragilizar a narrativa de que os altos preços de medicamentos são necessários para sustentar os custos de P\&D (COSTANTINI; WALENSKY, 2019) e chamam a atenção para um possível abuso dos monopólios patentários para se praticar preços exorbitantes no mercado farmacêutico.

Com frequência, alega-se que o custo estimado para se colocar um novo medicamento no mercado é de US\$2,56 bilhões (DIMASI; GRABOWSKI; HANSEN, 2016). Entretanto, além de este estudo ter sido bastante criticado por sua falta de transparência, pela fonte de seus dados e por suas fontes de financiamento (COLLIER, 2009; MÉDECINS SANS FRONTIÈRES, 2016), uma estimativa realizada pela DNDi tem enfraquecido ainda mais suas conclusões, chegando a apontar um valor mais que 10 vezes mais baixo, em torno de US\$110 milhões e US\$170 milhões para se desenvolver um novo medicamento (DRUGS FOR NEGLECTED DISEASES INITIATIVE, 2014; MAXMEN, 2016). Essa controvérsia, longe de ser solucionada facilmente, cumpre também a função de destacar a relevância de se discutirem regulamentações que garantam meios mais transparentes de divulgação dos custos de P\&D, especialmente por se tratar de um setor tão importante para os interesses de saúde pública.

A transparência dos custos reais de $\mathrm{P} \& \mathrm{D}$ seria crucial para se compreender mais profundamente a justiça da política de propriedade intelectual e das estratégias de precificação executadas pelas companhias biofarmacêuticas. Dessa forma, os governos teriam uma perspectiva mais clara do funcionamento do setor e poderiam ter uma atuação mais incisiva na regulamentação dessas condutas. Além disso, a impossibilidade de se avaliarem os custos reais de P\&D prejudica a própria inovação farmacêutica, dada a dificuldade de se determinar qual seria o modelo de incentivo à inovação mais efetivo, capaz de equilibrar as necessidades de saúde pública e os interesses do setor privado (MÉDECINS SANS FRONTIÈRES, 2016).

Sendo assim, uma primeira opção para se melhorar o cenário global de inovação seria que as companhias biofarmacêuticas tomassem iniciativas voluntárias de compartilhamento de informações sobre os custos de pesquisa, desenvolvimento e produção, bem como sobre a realização de testes clínicos, sobre as regulamentações existentes e sobre as estratégias de precificação de seus produtos. Outra opção seria que os governos adotassem medidas obrigatórias a exigirem transparência dos custos de desenvolvimento em troca de investimento de recursos públicos - ou de outras recompensas, como 
prioridade de análise pelos órgãos públicos, créditos fiscais ou prêmios. Além disso, os governos poderiam incluir essa exigência como parte de acordos de licenciamento, nos casos em que o desenvolvimento do composto químico tenha sido inicialmente feito pelo setor público e, depois, tenha sido continuado pelo setor privado (MÉDECINS SANS FRONTIÈRES, 2016).

Nesse contexto, também é relevante notar que nem todos os custos de desenvolvimento de novos medicamentos são suportados exclusivamente pela indústria. Nos EUA, por exemplo, a $\mathrm{NIH}$ investiu recursos próprios em todos os 210 novos medicamentos aprovados pela FDA, entre 2010 e 2016, totalizando mais de US\$ 110 bilhões (CLEARY et al., 2018). Assim, destaca-se que o SOF não foi uma exceção, já que a $\mathrm{P} \& \mathrm{D}$ deste medicamento, em suas diferentes fases, recebeu recursos substanciais tanto da NIH quanto do Departamento de Assuntos de Veteranos dos EUA, ambos dos EUA (COSTANTINI; WALENSKY, 2019).

De fato, os verdadeiros custos de P\&D de novos medicamentos para a indústria são ainda um tema obscuro, dado que esse ambiente tem se mostrado intensamente marcado pela falta de transparência. Todavia, além dos dados apresentados acima, um relatório de 2016 do Congresso americano faz afirmações importantes ao apontar que os preços cobrados pelos medicamentos não são relacionados aos seus respectivos custos de desenvolvimento e que as sociedades empresárias, somente após o término da fase de $\mathrm{P} \& \mathrm{D}$, fixam os preços de seus produtos com o intuito de maximizar lucros (US DEPARTMENT OF HEALTH AND HUMAN SERVICES, 2016). Vários exemplos que comprovam essa afirmação podem ser encontrados também no trabalho desenvolvido por Costantini e Walensky (2019) e, mais especificamente, no caso do SOF.

Com a desconstrução paulatina dos argumentos apresentados pela indústria farmacêutica, uma nova narrativa parece emergir nesse cenário de disputa social. Em vez de utilizarem a recuperação dos investimentos em P\&D como justificativa para os altos preços dos medicamentos, as sociedades empresárias começam a justificá-los com base em um suposto valor da inovação para o paciente e para o sistema de saúde como um todo (MÉDECINS SANS FRONTIÈRES, 2016).

No caso do SOF, por exemplo, diante da repercussão global gerada pelos preços abusivos praticados pela Gilead, a sociedade empresária tem justificado as suas estratégias de precificação como uma recompensa devida a uma suposta economia para os pacientes e para o sistema de saúde no qual estão inseridos, porque, na ausência de seu tratamento inovador, os pacientes só poderiam recorrer a tratamentos e transplantes de fígado extremamente custosos. Dessa forma, de acordo com esta narrativa, os recursos economizados pela utilização do novo medicamento deveriam ser direcionados para a própria companhia (MÉDECINS SANS FRONTIÈRES, 2016; REUTERS, 2014).

Este é um ponto de inflexão importante da narrativa utilizada para se justificarem as estruturas do atual sistema de propriedade intelectual e merece uma atenção detida por parte do debate político contemporâneo. De acordo com a perspectiva morfogenética, adotada por Sell (2003), as estruturas do atual sistema inauguram um novo ciclo de transformação e dão lugar à disputa social entre os arquitetos da estrutura vigente, que buscam a maximização de seus próprios poderes, e seus 
opositores, que buscam novas formas de organização institucional. Nesse sentido, diante da fragilização do discurso que justifica o monopólio patentário e os altos preços de medicamentos, com base na necessidade de se recuperar os investimentos realizados em $\mathrm{P} \& \mathrm{D}$, é possível perceber a tentativa de agentes da indústria farmacêutica de alterar a narrativa e continuar justificando as mesmas práticas, dessa vez, com base em um suposto valor da inovação para a sociedade como um todo.

Essa é uma narrativa que a proxima a estratégia de precificação de medicamentos essenciais a qualquer bem de consumo ou artigo de luxo, que têm seus preços fixados com base nos seus respectivos valores percebidos e não em seus custos reais de produção adicionados a um lucro razoável. Para além dos problemas éticos envolvidos nessa escolha, há uma diferença substancial entre essas categorias de produtos que não podem ser negligenciada: quando a saúde ou a vida de um paciente depende diretamente do acesso a determinado medicamento, a sua disposição para comprá-lo é, em grande medida, independente do preço do produto. Isso significa dizer que as sociedades empresárias do setor farmacêutico, sob a égide de seus monopólios patentários, possuem a liberalidade de aumentar os preços de seus produtos muito além dos seus custos de produção e a demanda continuará alta, independentemente do preço cobrado ${ }^{14}$ (MÉDECINS SANS FRONTIÈRES, 2016).

Nesse sentido, quando medicamentos, como o SOF, são precificados de maneira exorbitante, há a necessidade de se racionar cuidados de saúde fundamentais para a vida de milhões de pessoas, de modo que somente aqueles que podem pagar, possuem bons seguros de saúde ou dispõem de um amplo sistema público de saúde têm acesso ao tratamento necessário para suas respectivas enfermidades. Não obstante essa problemática também afete diretamente países desenvolvidos como os EUA, a Inglaterra e a França, sem dúvidas, ela repercute mais severamente em países mais empobrecidos, nos quais preços acessíveis alcançam uma importância vital para uma enorme quantidade de pessoas (MÉDECINS SANS FRONTIÈRES, 2016).

Com efeito, no caso em estudo, é possível observar que as estratégias de patenteamento, licenciamento e precificação da Gilead parecem ser um fator severamente restritivo ao acesso da população necessitada ao SOF e, consequentemente, ao tratamento de VHC desenvolvido pela DNDi e seus parceiros. Assim, ao se contextualizar esse fenômeno em um cenário mais amplo, faz-se necessário discutir formas de superação dos problemas impostos pelas estruturas atuais do sistema de propriedade intelectual e pelas estratégias institucionais de seus agentes (SELL, 2003).

$\mathrm{Da}$ mesma forma que as estruturas globais erigidas pelo TRIPS criam novos agentes dedicados à maximização de seus próprios interesses e ao fortalecimento dos direitos de propriedade intelectual, essas mesmas estruturas também são responsáveis por criar novos agentes que resistem

\footnotetext{
14 "Geralmente, admite-se que os produtos farmacêuticos não podem ser considerados simples mercadorias por basicamente dois motivos: em primeiro lugar, porque os consumidores não estão em posição de julgar, por exemplo, a qualidade dos medicamentos e, por outro lado, é necessário que haja um sistema de controle e vigilância por parte do Estado; em um segundo momento, porque os medicamentos desempenham um papel social de elevada importância, na medida em que fazem parte da viabilidade da realização de um direito humano fundamental - o direito à saúde. Pode-se considerar, dessa forma, o medicamento como um bem público, sublinhando o direito de todo o cidadão ao seu acesso." (ZAMPIERI, 2015, p. 205-206).
} 
a esse status quo e tenta estabelecer novos arranjos institucionais, baseados em outros princípios e outros paradigmas (SELL, 2003). A partir da descrição do caso acima, é possível perceber que a DNDi parece se enquadrar nesse último grupo de agentes, que visam à alteração das instituições e das estruturas nas quais está inserida.

De fato, chama a atenção o contraste existente entre os efeitos da propriedade intelectual nas possibilidades de acesso ao RDV e ao SOF. Enquanto, no caso do RDV, a política de propriedade intelectual adotada pela DNDi e pelos seus parceiros ampliaram o acesso da população ao medicamento, no caso do SOF, as estratégias adotadas pela Gilead restringiram severamente o acesso a este medicamento, sobretudo, para aqueles que mais precisariam utilizá-lo. Sob a égide de um mesmo sistema de propriedade intelectual, portanto, foi possível se observarem condições de acesso bastante distintas a inovações farmacêuticas essenciais para o mesmo tratamento.

Nesse ponto específico, poder-se-ia argumentar que se trata de uma situação óbvia, visto como a DNDi é uma organização sem fins lucrativos e a Gilead, por sua vez, é uma sociedade empresária guiada pela lucratividade e pelos interesses de seus acionistas. Todavia, é relevante destacar que, no modelo de negócios praticados pela DNDi, está incluída a parceria com outros atores privados com fins lucrativos. Exemplo disso pode ser observado no próprio caso do RDV, tanto no contrato de licenciamento entre a DNDi e a Presidio, quanto nas parcerias com Insud Pharma e com o Labortorio Elea Phoenix, na América Latina.

Ainda, nesse sentido, vale destacar a atuação da Pharco em conjunto com o MPP, que ampliaram consideravelmente o acesso da população ao RDV, sem prejudicar a sustentabilidade dos investimentos realizados. Como já foi mencionado, se, por um lado, a licença celebrada entre o MPP e a Pharco para o RDV inclui royalties sobre as vendas líquidas de 4\% nos países de renda baixa e de $7 \%$ nos países de renda média, por outro, tendo em vista o interesse público de se ampliar a acessibilidade ao medicamento, a Pharco renunciou ao seu direito aos royalties relacionados às formulações pediátricas e autorizou a transferência de tecnologia aos sublicenciados do MPP (MEDICINES PATENT POOL, 2017).

Além disso, como já foi demonstrado acima, a falta de transparência nos custos reais de $\mathrm{P} \& \mathrm{D}$ dificultam a discussão acerca da lucratividade das sociedades empresárias do setor farmacêutico. Dessa maneira, não é possível avaliar com clareza suas estratégias de patenteamento, licenciamento e precificação, bem como as justificativas relacionadas a elas. Esse obstáculo representa uma grande obstrução para a elaboração de políticas públicas eficientes e de um modelo de incentivo à inovação efetivo (MÉDECINS SANS FRONTIÈRES, 2016).

Sendo assim, a discussão que se apresenta não divide o cenário entre aqueles que visam a possibilitar o acesso a medicamentos essenciais para a população necessitada e aqueles que buscam o lucro. Afinal, com base na atuação da DNDi e seus parceiros, é possível argumentar que a realidade é mais complexa e que esses interesses podem coexistir no âmbito de um projeto colaborativo. A discussão que se impõe é justamente sobre a pertinência de estratégias que visem exclusivamente à 
lucratividade, em detrimento dos interesses de saúde pública, e sobre as possíveis limitações a este comportamento.

De qualquer forma, a política de propriedade intelectual adotada pela DNDi e pelos seus parceiros poderia representar um importante avanço. Sua replicação poderia ser uma boa iniciativa para fomentar inovações acessíveis para a população. Nos últimos anos, a DNDi tem explorado cada vez mais métodos de colaboração fundados no paradigma da inovação aberta (DRUGS FOR NEGLECTED DISEASES INITIATIVE, 2017) e se dedicado especialmente às necessidades de tratamentos mais urgentes das populações mais empobrecidas. Para isso, a instituição se baseia em um modelo virtual de $\mathrm{P} \& \mathrm{D}$ e implementa seus programas farmacêuticos em colaboração com parceiros públicos e privados de todo o mundo. Segundo a própria instituição, esse modelo permite um controle melhor dos custos de desenvolvimento de novos medicamentos e proporciona uma alta flexibilidade, apesar de não poder prescindir de acordos colaborativos sólidos com os principais atores do setor biomédico (DRUGS FOR NEGLECTED DISEASES INITIATIVE, 2019b).

A DNDi possui diferentes tipos de acordos estabelecidos com seus parceiros, entre eles, destacam-se, por exemplo, os acordos de serviços de pesquisa, acordos de transferência de materiais, acordos de pesquisa e licenciamento, acordos de colaboração, acordos de estudos clínicos e acordos financeiros. No que se refere especificamente aos acordos de pesquisa e licenciamento, a propriedade intelectual se torna um elemento central, ficando, geralmente, sob a propriedade dos parceiros da DNDi e, em alguns casos, em copropriedade. Contudo, a DNDi possui algumas exigências mínimas nessa matéria (cláusulas de licenciamento), para que o produto final da parceria possa ser disponibilizado de maneira acessível à população (DRUGS FOR NEGLECTED DISEASES INITIATIVE, 2019c).

De maneira geral, a política de propriedade intelectual da DNDi é guiada por dois princípios: a necessidade de garantir que os medicamentos sejam igualmente acessíveis para os pacientes que delas necessitam e o desejo de desenvolver, sempre que possível, medicamentos como bens públicos. Assim, a abordagem da DNDi no âmbito da propriedade intelectual é pragmática e as decisões relacionadas à aquisição de patentes, aos termos de apropriação e aos termos de licença são elaboradas caso a caso. Como a DNDi sempre coloca em primeiro lugar as necessidades dos pacientes negligenciados, as negociações relativas à propriedade intelectual são direcionadas para obter as melhores condições possíveis para eles. Isso significa dizer, em suma, que a instituição trata as decisões relacionadas à propriedade intelectual como um meio de garantir o acesso e encorajar futuras inovações, tendo como objetivo precípuo o avanço tecnológico na área da saúde (DRUGS FOR NEGLECTED DISEASES INITIATIVE, 2019a).

Entretanto, as circunstâncias fáticas podem exigir uma complexificação da política de propriedade intelectual da entidade. A DNDi reconhece que a propriedade intelectual, que deverá ser sempre a exceção e não a regra, possui um papel estratégico na negociação com parceiros de determinados projetos e, em alguns casos, pode ser utilizada pela entidade para garantir o controle 
do processo de P\&D (DRUGS FOR NEGLECTED DISEASES INITIATIVE, 2019a). Além disso, dentro dessa abordagem pragmática, a propriedade intelectual também é utilizada com o intuito de alavancar importantes projetos e atrair parceiros. Isso pode ser observado na apresentação do modelo de negócios da entidade, no qual a DNDi apresenta os principais benefícios para as sociedades empresárias do setor biotecnológico em um eventual trabalho conjunto com a instituição (DRUGS FOR NEGLECTED DISEASES INITIATIVE, 2019b).

Essa perspectiva pragmática em relação aos direitos de propriedade intelectual tem sido considerada uma forma inovadora de se lidar com o descompasso existente entre os objetivos precípuos do sistema de propriedade intelectual e seus efeitos na realidade, sobretudo no que se refere ao grave caso das doenças negligenciadas. Nesse sentido, Feres, Silva e Moreira (2015, p. 17) defendem que a forma de atuação da DNDi representa uma tentativa de buscar novos horizontes interpretativos do sistema vigente e deveria ser replicado, na medida em que:

a organização atua paralelamente à política de propriedade intelectual, às vezes junto dela e por vezes fora, com o objetivo de minimizar o descaso do poder público, bem como do setor privado (indústrias farmacêuticas), com a pesquisa e desenvolvimento de fármacos para prevenir, combater e controlar as doenças negligenciadas.

Entendimento semelhante poder ser encontrado na perspectiva apresentada por Tresse (2015, p. 95), que, apesar de considerar que esse sistema colaborativo apresenta limitações e que não é capaz de substituir o papel fundamental do Estado nessa questão, reconhece que:

o fomento às iniciativas colaborativas através de parcerias com instituições públicas e privadas possui impacto relevante na indução do fluxo de conhecimento no campo das doenças negligenciadas, sem que para isso, seja necessário reforçar o direito de exclusividade relacionados à propriedade intelectual.

A seu turno, Barbeitas (2019) vai ainda mais longe e destaca que a DNDi se distingue das Parcerias Público-Privadas (PPP) tradicionalmente surgidas durante a epidemia de VIH. Segundo a autora, apesar de essas PPPs terem sido muito importantes para a exploração das potencialidades colaborativas entre diversos atores envolvidos no processo de inovação farmacêutica, a maioria delas se dedicou a medidas paliativas, como a doação de medicamentos, e não priorizaram as doenças mais negligenciadas, tais como leishmanioses, doença de Chagas e doença do sono. Enquanto isso, para ela, a DNDi, com seu modelo inovador, deveria ser considerada uma Parceria de Desenvolvimento Produtivo (PDP) original, capaz de fomentar o desenvolvimento tecnológico no sul global e de proporcionar soluções de longo prazo para as doenças negligenciadas (BARBEITAS, 2019).

Outra perspectiva crucial para se compreender esse fenômeno é trazida pela abordagem de Abecassis et al. (2019), na qual a DNDi é considerada uma PDP de características singulares e que poderia ser mais bem compreendida como um common. De acordo com os autores, a política de 
propriedade intelectual da entidade seria um dos fatores que a caracterizaria como tal, já que, desde o início, a DNDi se distingue das práticas impostas pelo TRIPS, colocando o acesso aos tratamentos como sua prioridade máxima e concebendo o sistema de propriedade intelectual como um grupo de direitos compartilhados (ABECASSIS et al., 2019).

É bem verdade, no entanto, que independentemente do modelo de atuação da DNDi e de seus benefícios, este não pode ser considerado uma regra no mercado farmacêutico global. Ao contrário, como se pode observar, o modelo de negócios e a política de propriedade intelectual adotados pela entidade parecem se configurar mais como uma exceção institucional nas estruturas do sistema de propriedade intelectual vigente. Sendo assim, apesar de o estudo e a replicação desse modelo possuírem uma grande importância para inovação de novos medicamentos no futuro, casos como o do SOF chamam a atenção para medidas mais urgentes a serem tomadas.

Nesse caso em específico, uma primeira medida tomada parece ter sido o indeferimento dos pedidos de patente relacionados ao SOF. Na Índia, por exemplo, em uma importante demonstração de participação ativa da sociedade civil, em novembro de 2013 e em março de 2014, a Delhi Network of Positive People $(D N P+)$ e a I-MAK protocolaram oposições a importantes pedidos de patente para o SOF. E, em setembro de 2014, as organizações Asia Pacific Network of People Living with HIV (APN+), Sankalp Rehabilitation Trust e Hepatitis Coalition Nagaland protocolaram outra oposição. Além disso, já como uma representação concreta da atual estatal, no Egito, a exclusividade patentária já foi indeferida duas vezes pelo escritório de patente do país, por falta de novidade e atividade inventiva (INTERNATIONAL TREATMENT PREPAREDNESS COALITION, 2015).

De acordo com Priti Radhakrishnan, Diretora de Acesso a Tratamentos, da I-MAK, ao desobstruir o acesso à versão genérica do SOF, os governos dos países excluídos do programa de licenças voluntárias da Gilead economizariam, pelo menos, US\$ 60 bilhões. Para ela, é urgente que os países tomem medidas concretas para indeferir os pedidos de patente relacionados ao SOF e para garantir que esse medicamento esteja disponível para todos aqueles cujas próprias vidas dependem disso (INTERNATIONAL TREATMENT PREPAREDNESS COALITION, 2015).

Nesse mesmo sentido, Arair Azambuja, presidente do Movimento Brasileiro de Luta contra as Hepatites Virais (MBHV) e membro do Fórum Social Brasileiro para Enfrentamento de Doenças Infecciosas e Negligenciadas (FSBEIN), defende a necessidade de redução dos preços do SOF e afirma que, com o dinheiro economizado, seria possível realizar campanhas diagnósticas, além de tratar pacientes em estágios iniciais da doença. Segundo ele, as projeções mostram que a cura universal e a erradicação da doença seriam possíveis no Brasil, caso a patente desse medicamento não fosse concedida e pudessem ser utilizados medicamentos genéricos acessíveis (DRUGS FOR NEGLECTED DISEASES INITIATIVE, 2018b).

Uma vez concedida a patente ao SOF em determinado país, todavia, o caminho parece apontar para a avaliação detida e para a aplicação das flexibilidades previstas no TRIPS, especialmente, no que se refere à utilização de licenças compulsórias ou de uso governamental. $\bigcirc$ exemplo mais 
proeminente de medidas ativas tomadas pelo governo, nesse sentido, surge na Malásia, onde mais de 500 mil habitantes estão infectados com o vírus da hepatite C (DIRECTOR-GENERAL OF HEALTH MALAYSIA, 2017).

A Malásia, assim como muitos outros países de renda média, foi inicialmente excluída do programa de licenciamento voluntário promovido pela Gilead e, portanto, não possuía acesso às versões genéricas e mais econômicas do SOF. Assim, os malásios infectados pelo VHC tinham que pagar cerca de US\$ 75 mil pelo tratamento da doença. Em 2016, contudo, a DNDi e o Ministério da Saúde da Malásia, a partir do marco do Plano Estratégico Nacional do país para as hepatites virais, começaram uma parceria para adotar uma abordagem de saúde pública para o VHC (DRUGS FOR NEGLECTED DISEASES INITIATIVE, 2018b).

Em parceria com a DNDi, o país liderou os testes clínicos STORM-C-1, investiu esforços estratégicos consideráveis e copatrocinou os estudos para avaliar a segurança e a eficácia da combinação RDV/SOF. Além disso, com o intuito de expandir o tratamento de pacientes com $\mathrm{AAD}$, a DNDi, a Pharco e a Pharmaniaga, uma sociedade empresária local de medicamentos genéricos, celebraram um acordo colaborativo para o registro do RDV e para a fabricação e distribuição de RDV e SOF genéricos. Esse acordo, além de visar à redução de preços desses medicamentos no território malásio e, potencialmente, em outros países do Sudeste Asiático, também abrangia a transferência de tecnologia da Pharco para a Pharmaniaga para produzir RDV localmente (DRUGS FOR NEGLECTED DISEASES INITIATIVE; PHARCO; PHARMANIAGA, 2017).

Diante desse contexto, em setembro de 2017, a Malásia expediu uma licença de uso governamental para obter SOF genéric ${ }^{15}$ (DIRECTOR-GENERAL OF HEALTH MALAYSIA, 2017). Essa medida foi muito importante para acelerar o acesso ao tratamento econômico da hepatite C nos hospitais públicos do país e adotar uma estratégia de acesso voltada ao paciente (DRUGS FOR NEGLECTED DISEASES INITIATIVE, 2018b). Em razão da postura ativa do governo malásio, atualmente, o tratamento composto pela combinação SOF/DCV pôde ser adquirido por US\$ 300 da Pharmaniaga e oferecido gratuitamente em cerca de 20 hospitais públicos do país (DRUGS FOR NEGLECTED DISEASES INITIATIVE, 2018b; FONG, 2018). Além disso, a pressão gerada pela proatividade do governo também fez com que o país fosse incluído no plano de licenças voluntárias da Gilead, possibilitando, assim, um ambiente mais competitivo à medida que outros fabricantes de medicamentos genéricos passem a ingressar no mercado nacional (DRUGS FOR NEGLECTED DISEASES INITIATIVE, 2018b).

\footnotetext{
${ }^{15}$ Em 2003, a Malásia já havia se tornado o primeiro país do mundo a expedir uma licença compulsória, quando o país precisou ampliar o acesso a medicamentos antirretrovirais importantes no combate ao VIH. E, continuando essa trajetória de liderança, em 2017, no caso do SOF, o país se tornou também o primeiro a expedir uma licença compulsória para o tratamento do VHC (DIRECTOR-GENERAL OF HEALTH MALAYSIA, 2017).
} 


\section{Considerações finais}

A resistência dos governos, de organizações internacionais e de grupos da sociedade civil oriundos de países periféricos evidencia a existência de um novo ciclo de disputas sociais inaugurado pelo TRIPS. Com base na análise do caso em tela, os interesses conflitantes, as vitórias e as derrotas sofridas durante o processo de negociação do tratado parecem reverberar até hoje. De um lado, agentes que representam os interesses da indústria farmacêutica defendem contundentemente seus monopólios patentários e, de outro, agentes que representam os interesses históricos de populações negligenciadas defendem direitos fundamentais para uma existência digna, como o direito à saúde e o acesso a tratamentos essenciais.

Nesse contexto, mesmo operando de dentro do sistema de propriedade intelectual, o programa de VHC da DNDi se apresenta como um modelo de resistência à implementação de estruturas e instituições que visam à maximização de interesses de alguns poucos agentes privados, em detrimento da maioria da população e de suas necessidades mais básicas. No entanto, embora a DNDi e seus parceiros tenham se esforçado para garantir a maior acessibilidade possível ao RDV, o objetivo precípuo desse empreendimento colaborativo não pôde ainda ser plenamente alcançado. No caminho, as estratégias de patenteamento, licenciamento e precificação praticadas pela Gilead em relação ao SOF foram determinantes para obstruir o acesso a um tratamento pangenotípico, simples e acessível para hepatite $\mathrm{C}$ - que é baseado na combinação RDV/SOF.

De qualquer forma, a análise do programa de VHC também foi capaz de apontar a própria DNDi como um modelo inovador a ser seguido pelos agentes que visam à transformação do paradigma atual do mercado farmacêutico. A política de propriedade intelectual da entidade e a sua priorização das necessidades de saúde pública parecem constituir um novo modelo de resistência aos condicionamentos estruturais impostos pelo TRIPS e pelos seus idealizadores. Em outras palavras, ainda que sob a égide de um mesmo sistema de propriedade intelectual, o caso estudado permitiu a aferição das potencialidades e limitações de modelos institucionais bastante distintos, chamando a atenção para a possibilidade de replicação do modelo mais promissor em detrimento daquele que falha em atender as necessidades mais básicas da população.

Em estudos futuros, contudo, ainda há a necessidade de se avaliar mais detidamente os detalhes do funcionamento proposto pela DNDi, os seus resultados e, principalmente, a sua sustentabilidade ao longo do tempo. Resta ainda investigar se esse modelo pode continuar se desenvolvendo dentro do atual sistema de propriedade intelectual e de suas próprias flexibilidades ou se o seu crescimento demandaria uma alteração profunda dessas estruturas.

Mesmo significando uma inovação e uma abertura relevante para a configuração futura de novos programas farmacêuticos, ademais, o caso estudado também apontou para a impossibilidade de se esquivar das disputas socioeconômicas existentes na realidade. Afinal, a ressignificação das instituições e a transformação das estruturas vigentes não poderiam ser realizadas sem a reação de 
agentes poderosos que movimentam largas somas de capital e de poder político. Sendo assim, além das próprias flexibilidades das estruturas na qual a DNDi está inserida, conclui-se que a entidade não prescinde da articulação colaborativa com sociedades empresárias do ramo farmacêutico, com o poder público e com a sociedade civil organizada para garantir a P\&D de tratamentos acessíveis para toda a população.

\section{REFERÊNCIAS}

ABECASSIS, Philippe et al. DNDi, a distinctive illustration of commons in the area of public health. AFD Research Papers Series, n. 2019-93, Feb. 2019. Disponível em: https://www.afd.fr/en/ dndi-distinctive-illustration-commons-area-public-health. Acesso em: 25 jul. 2019.

ANDRIEUX-MEYER, Isabelle et al. Safety and efficacy of ravidasvir plus sofosbuvir for 12 weeks in non-cirrhotic and 24 weeks in cirrhotic patients with hepatitis $C$ virus genotypes 1, 2, 3 and 6 : the STORM-C-1 phase II/III trial stage 1 results. In: THE INTERNATIONAL LIVER CONGRESS, 1., 2018, Paris. Proceedings [...]. Paris: European Association For The Study Of The Liver, 2018. Pôster. Disponível em: https://www.dndi.org/wp-content/uploads/2018/03/Andrieux-Meyer_STORM-C-1_phase_II_III_trial_EASL_ILC_2018.pdf. Acesso em: 24 jul. 2019.

BARBEITAS, Mady. The innovation system for leishmaniasis therapy in Brazil. In: CASSIER, Maurice; CORREA, Marilena (ed.). Health innovation and social justice in Brazil. Cham: Palgrave Macmillan, 2019. p. 109-134. Disponível em: https://www.palgrave.com/gp/book/9783319768335. Acesso em: 25 jul. 2019.

CASSIER, Maurice; CORREA, Marilena. A consortium in times of crisis: producing Brazilian sofosbuvir? In: CASSIER, Maurice; CORREA, Marilena (Ed.). Health innovation and social justice in Brazil. Cham: Palgrave Macmillan, 2019. p. 109-134. Disponível em: https://www.palgrave.com/ gp/book/9783319768335. Acesso em: 25 jul. 2019.

CENTER FOR DRUG EVALUATION AND RESEARCH. Application number: 2091950rig1s000. 2017. Disponível em: https://www.accessdata.fda.gov/drugsatfda_docs/ nda/2017/209195Orig1s000lbl.pdf. Acesso em: 24 jul. 2019.

CLEARY, Ekaterina Galkina et al. Contribution of NIH funding to new drug approvals 2010 2016. Proceedings of The National Academy of Sciences, [S. l.], v. 115, n. 10, p. 2329-2334, 12 fev. 2018. Disponível em: https://www.pnas.org/content/pnas/115/10/2329.full.pdf. Acesso em: 30 jul. 2019.

COLLIER, Roger. Drug development cost estimates hard to swallow. Canadian Medical Association Journal, [S. l.], v. 180, n. 3, p. 279-280, 3 fev. 2009. Disponível em: http://www.cmaj.ca/content/180/3/279.full. Acesso em: 30 jul. 2019.

COSTANTINI, Sydney; WALENSKY, Rochelle P. The costs of drugs in infectious diseases: branded, generics, and why we should care. The Journal Of Infectious Diseases, Oxford: Oxford University Press, p. 1-7, 19 mar. 2019. Disponível em: https://academic.oup.com/jid/advance-article/ doi/10.1093/infdis/jiz066/5385524. Acesso em: 30 jul. 2019. 
CRESSEY, Tim R. et al. Ravidasvir pharmacokinetics and ARV drugs interactions in HCV+/-HIV infected adults. In: CONFERENCE ON RETROVIRUSES AND OPPORTUNISTIC INFECTIONS, 1., 2018, Boston. Proceedings [...]. Boston: Croi Foundation, 2018. Pôster. Disponível em: http:// www.croiconference.org/sessions/ravidasvir-pharmacokinetics-and-arv-drugs-interactions-hcv-hiv-infected-adults. Acesso em: 25 jul. 2019.

DIMASI, Joseph A.; GRABOWSKI, Henry G.; HANSEN, Ronald W. Innovation in the pharmaceutical industry: New estimates of R\&D costs. Journal Of Health Economics, [S. l.]: Elsevier, v. 47, p. 20-33, maio 2016. Disponível em: https://www.sciencedirect.com/science/article/abs/pii/ S0167629616000291?via\%3Dihub. Acesso em: 23 jul. 2019.

DIRECTOR-GENERAL OF HEALTH MALAYSIA. Press Statement Minister of Health 20th September 2017 - Implementation of the Rights of Government for Sofosbuvir Tablet to Increase Access for Hepatitis C Treatment in Malaysia. 2017. Disponível em: https://kpkesihatan.com/2017/09/20/press-statement-minister-of-health-20th-september-2017-implementation-of-the-rights-of-government-for-sofosbuvir-tablet-to-increase-access-for-hepatitis-c-treatment-in-malaysia/. Acesso em: 23 jul. 2019.

DRUGS FOR NEGLECTED DISEASES INITIATIVE. An innovative approach to $r \& d$ for neglected patients: ten years of experience \& lessons learned by DNDi. Geneva: Drugs For Neglected Diseases Initiative, 2014. 24 p. Disponível em: https://www.dndi.org/wp-content/uploads/2009/03/DNDi_ Modelpaper_2013.pdf. Acesso em: 30 jul. 2019.

DRUGS FOR NEGLECTED DISEASES INITIATIVE. 2016 Annual report: Progress through Partnership. Genebra: Drugs For Neglected Diseases Initiative, 2017. 76 p. Disponível em: https://www. dndi.org/about-dndi/annual-reports/annualreport2016/. Acesso em: 10 jul. 2019.

DRUGS FOR NEGLECTED DISEASES INITIATIVE. Compañias farmacéuticas y organizaciones sin fines de lucro colaboran para proporcionar un tratamiento para que la Hepatitis $C$ sea accesible para pacientes de América Latina. 2018a. Disponível em: https://www.dndial.org/es/2018/comunicacion-e-informacion/es-press-releases/companias-farmaceuticas-y-organizaciones-colaboran-para-proporcionar-tratamiento-para-hepatitis-c-sea-accesible-america-latina/. Acesso em: 10 jul. 2019

DRUGS FOR NEGLECTED DISEASES INITIATIVE. Iniciativa Medicamentos para Doenças Negligenciadas e farmacêutica Pharco testam tratamento de baixo custo para hepatite $C$ com apoio dos governos da Malásia e Tailândia. 2016. Disponível em: https://www.dndi.org/2016/media-centre/langues-press-releases/dndi-pharco-hepc-malaysia-thailand-pt/. Acesso em: 10 jul. 2019.

DRUGS FOR NEGLECTED DISEASES INITIATIVE. Intellectual Property Policy: DNDi policies. 2019a. Disponível em: https://www.dndi.org/wp-content/uploads/2018/03/DNDi_Intellectual_Property_Policy.pdf. Acesso em: 10 jul. 2019.

DRUGS FOR NEGLECTED DISEASES INITIATIVE. Modelo de Negócios. 2019b. Disponível em: https://www.dndial.org/parcerias-estrategicas/modelo-negocios/. Acesso em: 10 jul. 2019.

DRUGS FOR NEGLECTED DISEASES INITIATIVE. Parceiros. 2019c. Disponível em: https:// www.dndial.org/parcerias-estrategicas/parceiros/. Acesso em: 10 jul. 2019.

DRUGS FOR NEGLECTED DISEASES INITIATIVE; PHARCO; PHARMANIAGA. Pharmaniaga, Pharco and DNDi sign agreement to provide affordable hepatitis C treatment in Malaysia. 2017. Disponível em: https://www.dndi.org/2017/media-centre/press-releases/pharmaniaga-pharco-dndi-agreement-affordable-hep-c-treatment-malaysia/. Acesso em: 23 jul. 2019. 
DRUGS FOR NEGLECTED DISEASES INITIATIVE. Uma abordagem de saúde pública para a epidemia de hepatite $C$ : levando o tratamento da hepatite $C$ aos pacientes negligenciados. Genebra: Drugs For Neglected Diseases Initiative, 2018b. 15 p. Disponível em: https://www.dndi.org/wp-content/uploads/2018/11/DNDi_HCV_2018_POR.pdf. Acesso em: 25 jul. 2019.

ESMAT, Gamal et al. Effectiveness of ravidasvir plus sofosbuvir in interferon-naïve and treated patients with chronic hepatitis C genotype-4. Journal Of Hepatology, [S. l.]: Elsevier BV, v. 68, n. 1, p. 53-62, set. 2017. Disponível em: https://www.ncbi.nlm.nih.gov/pubmed/28935432. Acesso em: 24 jul. 2019.

EUROPEAN ASSOCIATION FOR THE STUDY OF THE LIVER. EASL Recommendations on Treatment of Hepatitis C 2018. Journal of Hepatology, [S. l.]: Elsevier BV, v. 69, n. 2, p. 461-511, ago. 2018. Disponível em: https://www.journal-of-hepatology.eu/article/S0168-8278(18)31968-8/pdf. Acesso em: 24 jul. 2019.

FERES, Marcos Vinício Chein; SILVA, Alan Rossi; MOREIRA, Thaís Miranda. A DNDi e a política de propriedade intelectual: a zona intermediária da legalidade. In: SEMINÁRIO INTERNACIONAL DE DIREITOS HUMANOS E EMPRESAS, 2., 2015, Juiz de Fora. Anais [...]. Juiz de Fora: UFJF, 2015. p. 1-18. Disponível em: https://seminariosinternacionaisdireitoshumanoseempresas.files. wordpress.com/2015/10/artigo-completo-grupo-de-trabalho-ii-a-dndi-e-a-polc3adtica-de-propriedade-intelectual-a-zona-intermedic3a1ria-da-legalidade.pdf. Acesso em: 10 jul. 2019.

FONG, Loh Foon. Hope for hepatitis C patients. The Star Online, Kuala Lumpur, 2 mar. 2018. Disponível em: https://www.thestar.com.my/news/nation/2018/03/02/hope-for-hepatitis-c-patients-18-state-hospitals-offering-treatment-through-affordable-medicine/. Acesso em: 23 jul. 2019.

GILEAD SCIENCES INC. Chronic hepatitis $C$ treatment expansion: generic manufacturing for developing countries. 2015. Disponível em: https://www.gilead.com/ /media/\%20files/pdfs/other/ hcv\%20generic\%20agreement\%20fast\%20facts\%20101615\%20.pdf 2 la =en. Acesso em: 25 jul. 2019.

GILEAD SCIENCES INC. Epclusa ${ }^{\circledR}$ Registration In The Developing World. 2019. Disponível em: https://www.gilead.com/-/media/files/pdfs/aoem-registrations/epclusa_registeration.pdf?la =en\&hash=83CDB4E0C2D7FBF3DE87E9E5F5C60BE6. Acesso em: 24 jul. 2019.

GILEAD SCIENCES INC. License agreement. 2014. Disponível em: https://www.gilead.com/ /me$\mathrm{dia} / \mathrm{files} / \mathrm{pdfs} /$ other/2014_original_hcv_licensing_agreement.pdf?lla=en. Acesso em: 25 jul. 2019.

HATCH, Orrin G.; WYDEN, Ron. The price of sovaldi and its impact on the U.S. health care system. Washington: U.S. Government Publishing Office, 2015. 134 p. Disponível em: https://www.finance.senate.gov/imo/media/doc/1\%20The\%20Price $\% 20$ of\%20Sovaldi $\% 20$ and $\% 20$ Its $\% 20 I m p a c t \% 20$ on\%20the\%20U.S.\%20Health\%20Care\%20System\%20(Full\%20Report).pdf. Acesso em: 30 jul. 2019.

HILL, Andrew et al. Rapid reductions in prices for generic sofosbuvir and daclatasvir to treat hepatitis C. Journal Of Virus Eradication, London, v. 2, n. 1, p. 28-31, jan. 2016. Disponível em: https:// www.ncbi.nlm.nih.gov/pmc/articles/PMC4946692/pdf/jve-2-28.pdf. Acesso em: 25 jul. 2019.

INTERNATIONAL TREATMENT PREPAREDNESS COALITION. A step back for millions of people with hepatitis C. 2015. Disponivel em: http://itpcglobal.org/a-step-back-for-millions-of-people-with-hepatitis-c/. Acesso em: 25 jul. 2019 
IWAMOTO, Momoko et al. Identifying the optimal care model for HCV care in Cambodia, and overcoming barriers to decentralization and scale-up: Médecins Sans Frontières' (MSF) pilot program. In: WORLD HEPATITIS SUMMIT, 1., 2017, São Paulo. Proccedings [...]. São Paulo: World Hepatitis Summit, 2017. Pôster. Disponível em: http://www.worldhepatitissummit.org/docs/default-source/posters/49a_momokoiwamoto.pdf?sfvrsn=2. Acesso em: 24 jul. 2019.

LAZONICK, William et al. How Stock Buybacks Make Americans Vulnerable to Globalization. The Academic-industry Research Network, Cambridge, v. 2, n. 1, p. 1-16, 2016. Disponível em: http:// www.theairnet.org/v3/backbone/uploads/2016/03/Lazonick.BuybacksAndGlobalization_AIR-WP16-0301.pdf. Acesso em: 30 jul. 2019.

LOVE, James. Pharmaceutical global ReD was 7.9 percent of sales in 2010. 2011. Disponível em: https://www.keionline.org/21592. Acesso em: 30 jul. 2019.

MACHADO, Maíra Rocha. O estudo de caso na pesquisa em direito. In: MACHADO, Maíra Rocha (org.). Pesquisar empiricamente o direito. São Paulo: Rede de Estudos Empíricos em Direito, 2017. p. 357-389. Disponível em: http://reedpesquisa.org/publicacoes/volume-2-no-1-2014/. Acesso em: 30 jul. 2019.

MAXMEN, Amy. Busting the billion-dollar myth: how to slash the cost of drug development. Nature, [S. l.], v. 536, n. 7617, p. 388-390, ago. 2016. Disponível em: https://www.nature.com/news/ busting-the-billion-dollar-myth-how-to-slash-the-cost-of-drug-development-1.20469. Acesso em: 23 jul. 2019.

MEDICINES PATENT POOL. El Medicines Patent Pool y Pharco Pharmaceuticals firman una licencia para el ravidasvir, un medicamento prometedor para la hepatitis C. 2017. Disponível em: https://medicinespatentpool.org/uploads/2018/01/2017.04.El-Medicines-Patent-Pool-y-Pharco-Pharmaceuticals-firman-una-licencia-para-el-ravidasvir.pdf. Acesso em: 23 jul. 2019.

MÉDECINS SANS FRONTIÈRES. Lives on the edge: time to align medical research and development with people's health needs. Geneva: Médecins Sans Frontières, 2016. 52 p. Disponível em: https://msfaccess.org/lives-edge-time-align-medical-research-and-development-peoples-health-needs. Acesso em: 23 jul. 2019.

MÉDECINS SANS FRONTIÈRES. MSF secures lower price for generic hepatitis $C$ treatment. 2017. Disponível em: https://www.msf.org/msf-secures-lower-price-generic-hepatitis-c-treatment. Acesso em: 23 jul. 2019.

MOSER, Petra. Patents and innovation in economic history. National Bureau of Economic Research, [S. l.], p. 1-34, fev. 2016. Disponível em: https://www.nber.org/papers/w21964.pdf. Acesso em: 30 jul. 2019.

MSF ACCESS CAMPAIGN. Spotlight on: Trans-Pacific Partnership Agreement. 2018. Disponível em: https://msfaccess.org/spotlight-trans-pacific-partnership-agreement. Acesso em: 30 jul. 2019.

NG, Eric. Chinese biotech firm Ascletis first to apply for Hong Kong IPO under new rules. South China Morning Post, [S. 1.], 8 maio 2018. Disponível em: https://www.scmp.com/business/companies/article/2145082/chinese-biotech-firm-ascletis-first-apply-hong-kong-ipo-under-new. Acesso em: 23 jul. 2019. 
PHARMACEUTICAL RESEARCH AND MANUFACTURERS OF AMERICA. Advocacy: intellectual property. 2019. Disponível em: https://www.phrma.org/advocacy/intellectual-property. Acesso em: 30 jul. 2019.

PHARMACEUTICAL RESEARCH AND MANUFACTURERS OF AMERICA. 2015 biopharmaceutical research industry profile. Washington: Pharmaceutical Research And Manufacturers of America, 2015. 67 p. Disponível em: http://phrma-docs.phrma.org/sites/default/files/pdf/2015_phrma_profile.pdf. Acesso em: 30 jul. 2019.

POLARIS OBSERVATORY HCV COLLABORATORS. Global prevalence and genotype distribution of hepatitis C virus infection in 2015: a modelling study. The Lancet Gastroenterology \& Hepatology, [S. l.]: Elsevier, v. 2, n. 3, p. 161-176, 2017. Disponível em: https://www.thelancet.com/ action/showPdf? pii=S2468-1253\%2816\%2930181-9. Acesso em: 17 jul. 2019.

REUTERS. Insurers worry that $\$ 84,000$ hepatitis $\mathrm{C}$ drug sovaldi could break the bank. Newsweek, [S. l.], p. 1-2, 28 maio 2014. Disponível em: https://www.newsweek.com/insurers-worry-84000-hepatitis-c-drug-sovaldi-could-break-bank-252539. Acesso em: 30 jul. 2019.

SELL, Susan K. Private power, public law: the globalization of intellectual property rights. Nova Iorque: Cambridge University Press, 2003. 242 p.

STATISTA. Ranking of the 20 companies with the highest spending on research and development in 2018 (in billion U.S. dollars). 2019. Disponível em: https://www.statista.com/statistics/265645/ranking-of-the-20-companies-with-the-highest-spending-on-research-and-development/. Acesso em: 30 jul. 2019.

SWANSON, Ana. Big pharmaceutical companies are spending far more on marketing than research. The Washington Post, Washington, 11 fev. 2015. Disponível em: https://www.washingtonpost. $\mathrm{com} /$ news/wonk/wp/2015/02/11/big-pharmaceutical-companies-are-spending-far-more-on-marketing-than-research/? noredirect $=$ on\&utm_term $=.80 \mathrm{bf0f4c5ab4.} \mathrm{Acesso} \mathrm{em:} 30$ jul. 2019.

TIRRELL, Meg. Gilead to buy pharmasset for $\$ 11$ billion to win in hepatitis. Bloomberg, [S. l.], 2014. Disponível em: https://www.bloomberg.com/news/articles/2011-11-21/gilead-to-acquire-pharmasset-for-11-billion-to-add-hepatitis-c-medicines. Acesso em: 30 jul. 2019.

TRESSE, Vitor Schettino. Doenças negligenciadas e patentes de fármacos: uma análise da garantia ao direito à saúde através do novo paradigma colaborativo. 2015. 109 f. Dissertação (Mestrado em Direito) - Universidade do Estado do Rio de Janeiro, Rio de Janeiro, 2015.

UNITED STATES GOVERNMENT ACCOUNTABILITY OFFICE. Drug industry: profits, research and development spending, and merger and acquisition deals. Washington: United States Government Accountability Office, 2017. 78 p. Disponível em: https://www.gao.gov/assets/690/688472. pdf. Acesso em: 30 jul. 2019.

U.S. DEPARTMENT OF HEALTH AND HUMAN SERVICES. Prescription drugs: innovation, spending, and patient access. Washington: U.S. Department Of Health And Human Services, 2016. 147 p. Disponível em: https://delauro.house.gov/sites/delauro.house.gov/files/Prescription-Drugs-Innovation-Spending-and-Patient-Access-12-07-16.pdf. Acesso em: 30 jul. 2019.

WORLD HEALTH ORGANIZATION. Essential medicines and health products: prequalification of medicines. 2019. Disponível em: https://extranet.who.int/prequal/. Acesso em: 24 jul. 2019. 
WORLD HEALTH ORGANIZATION. Global hepatitis report 2017. Geneva: World Health Organization, 2017. 68 p. Disponível em: https://www.afro.who.int/sites/default/files/2017-06/ 9789241565455-eng.pdf. Acesso em: 30 jul. 2019.

WORLD HEALTH ORGANIZATION. Guidelines for the care and treatment of persons diagnosed with chronic hepatitis C virus infection. Geneva: World Health Organization, 2018a. 108 p. Disponível em: https://apps.who.int/iris/bitstream/handle/10665/273174/9789241550345-eng.pdf?ua=1. Acesso em: 24 jul. 2019.

WORLD HEALTH ORGANIZATION. Progress report on access to hepatitis $C$ treatment: focus on overcoming barriers in low - and middle-income countries. Geneva: World Health Organization, 2018b. 68 p. Disponível em: https://apps.who.int/iris/bitstream/handle/10665/260445/WHO-CDS-HIV-18.4-eng.pdf;jsessionid=9AC16EC2FB8CFE75BD77EC8DF69E417D? sequence=1. Acesso em: 24 jul. 2019.

WORLD TRADE ORGANIZATION. Acordo sobre Aspectos dos Direitos de Propriedade Intelectual Relacionados ao Comércio. 1994. Disponível em: http://www.inpi.gov.br/legislacao-1/27-trips-portugues1.pdf. Acesso em: 20 ago. 2019.

YIN, Robert K. Estudo de caso: planejamento e método. 5. ed. Porto Alegre: Bookman, 2015.

ZAMPIERI, Natália. A problemática dos monopólios das indústrias de medicamentos e o direito à saúde: o caso glivec. Espaço Jurídico Journal Of Law [EJJL], São Miguel do Oeste: Universidade do Oeste de Santa Catarina, v. 16, n. 1, p. 201-220, jun. 2015. Disponível em: https://portalperiodicos. unoesc.edu.br/espacojuridico/article/view/2822. Acesso em: 31 jul. 2019. 